\title{
A novel Arabidopsis phyllosphere resident Protomyces species and a re-examination of genus Protomyces based on genome sequence data
}

\author{
Kai Wang ${ }^{1}$, Timo Sipilä ${ }^{1,2}$ and Kirk Overmyer ${ }^{1 *}$ (D)
}

\begin{abstract}
Protomyces is an understudied genus of yeast-like fungi currently defined as phytopathogens of only Umbelliferae and Compositae. Species relationships and boundaries remain controversial and molecular data are lacking. Of the 82 named Protomyces, we found few recent studies and six available cultures. We previously isolated Protomyces strains from wild Arabidopsis thaliana, a member of Brassicaceae, a family distant from accepted Protomyces hosts. We previously sequenced the genomes of all available Protomyces species, and P. arabidopsidicola sp. nov. strain C29, from Arabidopsis. Phylogenomics suggests this new species occupied a unique position in the genus. Genomic, morphological, and physiological characteristics distinguished P. arabidopsidicola sp. nov. from other Protomyces. Nuclear gene phylogenetic marker analysis suggests actin 1 gene DNA sequences could be used with nuclear ribosomal DNA internal transcribed spacer sequences for rapid identification of Protomyces species. Previous studies demonstrated P. arabidopsidicola sp. nov. could persist on the Arabidopsis phyllosphere and Protomyces sequences were discovered on Arabidopsis at multiple sites in different countries. We conclude that the strain C29 represents a novel Protomyces species and propose the name of P. arabidopsidicola sp. nov. Consequently, we propose that Protomyces is not strictly associated only with the previously recognized host plants.
\end{abstract}

Keywords: Taphrinomycotina, Taphrinales, Protomycetaceae, Phyllosphere, Phylogenomics, Brassicaceae, Average nucleotide identity (ANI), Species delimitation, Carbon source utilization, One new taxon

\section{INTRODUCTION}

Protomyces is a genus of plant pathogenic fungi that cause tumour or gall symptoms within flowers, stems, leaves (especially leaf veins), and petioles on host plants exclusively in the families Umbelliferae (Apiaceae) and Compositae (Asteraceae) (Reddy and Kramer 1975; Kurtzman 2011). Members of the genus Protomyces have been previously defined based on the morphology of ascospores and vesicles, the host on which they cause disease, and the tissue within the host where they form

\footnotetext{
* Correspondence: kirk.overmyer@helsinki.fi

'Organismal and Evolutionary Biology Research Program, Faculty of Biological and Environmental Sciences, and Viikki Plant Science Centre, P.O. Box 65, Viikinkaari 1, Fl-00014 Helsinki, Finland

Full list of author information is available at the end of the article
}

reproductive structures (Kurtzman 2011; Reddy and Kramer 1975). Protomyces species have been stated to cause diseases on "Apiaceae, Compositae, Umbelliferae, and certain other plants" (Kurtzman and Sugiyama 2015; Kurtzman 2011), a claim supported by citations in Tubaki (1957) and Reddy and Kramer (1975). However, closer examination shows that the genus, as currently defined, only contains species pathogenic to plants in Compositae and Umbelliferae (Table 1).

Some confusion may arise from the dual naming of the plant families Apiaceae and Asteraceae, which are authorized alternative names for Umbelliferae and Compositae, respectively (Turland et al. 2018). Tubaki (1957) studied the three Protomyces species, $P$. inouyei, $P$. lactucaedebilis, and $P$.

(c) The Author(s). 2021 Open Access This article is licensed under a Creative Commons Attribution 4.0 International License, which permits use, sharing, adaptation, distribution and reproduction in any medium or format, as long as you give

appropriate credit to the original author(s) and the source, provide a link to the Creative Commons licence, and indicate if changes were made. The images or other third party material in this article are included in the article's Creative Commons licence, unless indicated otherwise in a credit line to the material. If material is not included in the article's Creative Commons licence and your intended use is not permitted by statutory regulation or exceeds the permitted use, you will need to obtain permission directly from the copyright holder. To view a copy of this licence, visit http://creativecommons.org/licenses/by/4.0/. 
Table 1 Accepted species of Protomyces.

\begin{tabular}{|c|c|c|c|c|c|c|c|}
\hline Species & Synonym & Host genera & $\begin{array}{l}\text { Host } \\
\text { family }\end{array}$ & $\begin{array}{l}\text { Source } \\
\text { b }\end{array}$ & ITS $^{c}$ & Strains $^{d}$ & Genome e \\
\hline P. gravidus & - & Ambrosia, Bidens & Compositae & A & $\begin{array}{l}\text { This study } \\
\text { (MK937055) }\end{array}$ & $\underline{Y-17093 ;}$ ATCC 64066 & $\begin{array}{l}\text { Wang et al. } 2019 \\
\text { (QXDP00000000) }\end{array}$ \\
\hline P. inouyei & - & Crepis & Compositae & A & $\begin{array}{l}\text { This study } \\
\text { (MK937056) }\end{array}$ & $\begin{array}{l}\text { CBS 222.57; YB-4354; YB- } \\
\text { 4365; NBRC 6898; IAM } \\
\text { 14512; ATCC 16175; } \\
\text { UAMH } 1743\end{array}$ & $\begin{array}{l}\text { Wang et al. } 2019 \\
\text { (QXDQ00000000) }\end{array}$ \\
\hline $\begin{array}{l}\text { P. } \\
\text { lactucaedebilis }\end{array}$ & - & Lactuca debilis & Compositae & $A$ & $\begin{array}{l}\text { This study } \\
\text { (MK937058) }\end{array}$ & $\begin{array}{l}\text { CBS 223.57; YB-4353; } \\
\text { Phaff 12-1054; NBRC } \\
6899\end{array}$ & $\begin{array}{l}\text { Wang et al. } \\
2019 \text {, Riley et al. } \\
2016 \\
\text { (QXDS00000000) }\end{array}$ \\
\hline $\begin{array}{l}P . \\
\text { macrosporust }\end{array}$ & $\begin{array}{l}\text { Physoderma } \\
\text { gibbosum, } \\
\text { P. cari }\end{array}$ & $\begin{array}{l}\text { Aegopodium, Ammi, Angelica, } \\
\text { Anthriscus, Archangelica, } \\
\text { Athamanta, Canopodium, Carum, } \\
\text { Caucalis, Cherophyllum, } \\
\text { Coriandrum, Ferula, Heracleum, } \\
\text { Hydrocotyle, Laserpitim, Ligusticum, } \\
\text { Meum, Onanthe, Pancicia, Parum, } \\
\text { Peucedanum, Pimpinella, Seseli, } \\
\text { Ssilaus, Thapsia, Trinia }\end{array}$ & Umbelliferae & A & $\begin{array}{l}\text { This study } \\
\text { (MK937059) }\end{array}$ & $\begin{array}{l}\text { Y-12879; PYCC 4286; } \\
\text { ATCC 56196 }\end{array}$ & $\begin{array}{l}\text { Wang et al. 2019 } \\
\text { (QXDT00000000) }\end{array}$ \\
\hline P. pachydermus & $\begin{array}{l}\text { P. } \\
\text { kreuthensis, } \\
\text { P. centarea, } \\
\text { P. crepidis, } \\
\text { P. } \\
\text { crepidicola, } \\
\text { P. crepidis- } \\
\text { paludosae, } \\
\text { P. picridis, } \\
\text { P. } \\
\text { kriegarianus, } \\
\text { P. crisii- } \\
\text { oleracei }\end{array}$ & $\begin{array}{l}\text { Aposeris, Centaurea, Crespis, } \\
\text { Criseum, Hyoseris, Hypochaeris, } \\
\text { Leontodon, Picris, Taraxacum. }\end{array}$ & Compositae & A & $\begin{array}{l}\text { This study } \\
\text { (MK937060) }\end{array}$ & $\begin{array}{l}\text { CBS 224.57; YB-4355; Y- } \\
\text { 6348; Y-27322; Y-27323, } \\
\text { DSM5500; NBRC 6900; } \\
\text { IAM 14514; ATCC 90575; } \\
\text { MUCL } 38937\end{array}$ & $\begin{array}{l}\text { Wang et al. } 2019 \\
\text { (QXDU00000000) }\end{array}$ \\
\hline P. inundatus & $\begin{array}{l}\text { P. helosciadii, } \\
\text { Taphridium } \\
\text { innundatus }\end{array}$ & Apium, Daucus, Sium & Umbelliferae & $B, C$ & $\begin{array}{l}\text { This study } \\
\text { (MK937057) }\end{array}$ & $\begin{array}{l}\text { Y-6349; Y-6802; IAM 6847; } \\
\text { ATCC 28148, ATCC 22667; } \\
\text { ATCC 28130; ATCC 22666, }\end{array}$ & $\begin{array}{l}\text { Wang et al. } 2019 \\
\text { (QXDR00000000) }\end{array}$ \\
\hline $\begin{array}{l}P . \\
\text { arabidopsidicola }\end{array}$ & - & Arabidopsis thaliana & Brassicaceae & $\mathrm{D}$ & $\begin{array}{l}\text { This study } \\
\text { (LT602858) }\end{array}$ & HAMBI3697, DSM 110145 & $\begin{array}{l}\text { Wang et al. } 2019 \\
\text { (QXMI00000000) }\end{array}$ \\
\hline P. burenianus & & Galinsoga parviflora & Compositae & $E$ & None & None & None \\
\hline P. cirsii-oleracei & & Cirsium oleraceum & Compositae & $\mathrm{F}$ & None & None & None \\
\hline P. andinus & P. giganteus & Bidens, Hypochoeris & Compositae & A & None & None & None \\
\hline P. burenianus & - & Galinsoga & Compositae & A & None & None & None \\
\hline P. grandisporus & - & Ambrosia & Compositae & A & None & None & None \\
\hline P. matricariae & - & Matricaria & Compositae & $A$ & None & None & None \\
\hline P. sonchi & - & Sonchus & Compositae & A & None & None & None \\
\hline
\end{tabular}

aHost plant family: A single family name listed below, both valid names for the same family are listed here; Compositae (Asteraceae), Umbelliferae (Apiaceae), or Brassicaceae (Cruciferae). ${ }^{b}$ Sources: A, Reddy and Kramer (1975); B, Kurtzman et al. (2011); C, Kurtzman and Robnett (1998); D, Wang et al. (2019); E, Bacigálová (2008); F, Bacigálová et al. (2005). ' Availability of ITS: Internal Transcribed Spacer sequences (with Genebank accession numbers in parentheses) ${ }^{\mathrm{d}}$ Thirty major yeast culture collections were queried for availability of Protomyces species in July 2019. The accession numbers of available strains are listed below. Accession numbers that are underlined indicate type strain cultures, which are also the strains used in this study. The full list of queried collections is available in Supplemental file 1. Collections with strains of Protomyces species available are listed below: Microbial Domain Biological Resource Centre, Helsinki, Finland (HAMBl; https://www.helsinki.fi/en/infrastructures/biodiversity-collections/infrastructures/microbial-domain-biological-resource-centre-hambi); The German Collection of Microorganisms and Cell Cultures GmbH, Braunschweig, Germany (DSMZ; www.dsmz.de); The Japan Collection of Microorganisms, Koyadai, Tsukuba, Ibaraki, Japan (JCM/IAM; jcm.brc.riken.jp/en/); Biological Resource Center NITE, Chiba, Japan (NBRC; www.nite.go.jp/en/nbrc); CBS-KNAW Fungal Biodiversity Centre, Utrecht, The Netherlands (CBS; http://www.westerdijkinstitute.nl/Collections); The Portuguese Yeast Culture Collection, Caparica, Portugal (PYCC; http://pycc.bioaware.com/); Agricultural Research Service Culture Collection, Peoria, IL, USA (Y-/YB-/NRRL; nrrl.ncaur.usda.gov); American Type Culture Collection, Manassas, VA, USA (ATCC; www.atcc.org); University of California Phaff Culture Collection, Davis, CA, USA (UCD-FST; http://phaffcollection.ucdavis.edu); Belgian Coordinated Collection of Microorganisms, Louvain-la-Neuve, Belgium (BCCM/MCLU; http://bccm.belspo.be/); The UAMH Centre for Global Microfungal Biodiversity, Toronto,

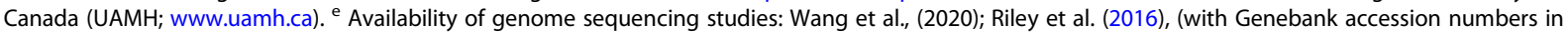
parentheses.) † Type species, Protomyces Unger 1833 
pachydermus, which are pathogenic on Compositae. Reddy and Kramer's (1975) taxonomic revision of Protomycetaceae indicates that, for all the genera in Protomycetaceae, including all Protomyces species, the hosts are restricted to Umbelliferae and Compositae. They accepted 10 species in Protomyces, but rejected 61 previously proposed Protomyces species, based on their morphology, lack of materials for examination, or association with host plants outside of the families Umbelliferae and Compositae. Later works expanded the number of known species in the genus Protomyces (Bacigálová 2008; Bacigálová et al. 2005; Kurtzman and Robnett 1998; Kurtzman 2011). Bacigálová et al. (2005) list host plants in Cichoriaceae, now treated as a subfamily Cichorioideae within Compositae (Funk and Chan 2009).

There is a lack of molecular data on species of Protomyces and other Protomycetales genera. Indeed, as previously noted (Kurtzman 2011), there is need for increased efforts in the collection and molecular analysis of these fungi. Our survey of 30 major yeast culture collections (Supplemental file 1; Boundy-Mills et al. 2016) revealed that as of July 2019 there were only six Protomyces species with strains available for analysis, including one verified ex-type strain for each of these species (Table 1).

The genus Protomyces was established by Unger (1833) with the type species $P$. macrosporus. The sexual cycle is initiated from the diploid hyphal morph (Sugiyama et al. 2006), which occurs primarily during infection in plant tissues. The haploid (asexual) morph is yeast-like, unicellular, reproduces by budding, and is easy to culture. Carotenoid pigments are formed when culturing on artificial growth media (Van Eijk and Roeymans 1982) and colonies are usually yellow to pink. The phylogenetic placement of Protomyces has been debated since their first discovery (Kurtzman 2011). Protomyces is the type genus of the family Protomycetaceae, which also contains genera of currently doubtful phylogenetic relationships and generic boundaries (Reddy and Kramer 1975; Kurtzman 2011), including the soil and insect associated Saitoella, where the genome of one species has been sequenced (Nishida et al. 2011), and the Protomyces-like plant pathogens, Burenia, Protomycopsis, Taphridium, and Volkartia, for which there are currently no cultures or molecular data available.

Carbon source utilization profiles remain a quick and useful additional tool for the identification of yeast species (Kurtzman et al. 2011) and recent fungal genome sequencing projects have begun to address the relationships between biochemical traits and gene content (Riley et al. 2016). The use of molecular analysis unambiguously placed Protomyces in the ascomycete subphylum Taphrinomycotina, as a sister clade to the genus Taphrina in the order Taphrinales (Walker 1985; Nishida and Sugiyama 1994; Kurtzman and Robnett 1998; James et al. 2006; Sugiyama et al. 2006; Hibbett et al. 2007; Kurtzman 1993a). It has been noted in the closely related genus Taphrina that the nuclear ribosomal DNA (nrDNA) 26S large-subunit D1/D2 domain (D1/D2) and especially nrDNA internal transcribed spacer (ITS) markers gave resolution to the genus level, but some species could not be resolved (Rodrigues and Fonseca 2003). In general, there is a need in some fungal taxa to develop lineage specific secondary phylogenetic markers to achieve reliable species level identification; DNA markers, such as actin, translation elongation factors, ribosomal polymerase subunits and tubulin, have been described and applied for this purpose (Stielow et al. 2015).

It has been suggested that members of Protomyces, its sister genus Taphrina, and some other members of Taphrinales, may have retained the life-styles of early Ascomycota, due to their many ancestral features and basidiomycete-like traits, such as high genomic GC content (Sugiyama et al. 1996; Wang et al. 2019), thick walled "chlamydospore" reproductive or resting cells (de Bary and Garnsey 1887; Mix 1924), basidiospore-like naked asci (Sadebeck 1884; Lohwag 1934), enteroblastic budding pattern (Sugiyama et al. 1996; Von Arx and Weijman 1979), Q-10 ubiquinone system (Sugiyama et al. 2006), and the presence of a putative dual hybrid histidine kinase (Wang et al. 2019). These similarities are also illustrated by the many instances, in which species within the Taphrinales have been misclassified amongst the basidiomycetes, or vice versa (Piepenbring and Bauer 1997; de Bary and Garnsey 1887; Reddy and Kramer 1975; Nishida and Sugiyama 1995). Due to their phylogenetic position and these characteristics, these species are of considerable evolutionary interest.

Here we describe a Protomyces strain C29, isolated from the phyllosphere of wild Arabidopsis thaliana, as a new Protomyces species, $P$. arabidopsidicola. The delimitation of the genus Protomyces and boundaries of species within it are also examined here in the light of new genome sequencing data.

\section{MATERIALS AND METHODS}

For comparison, confirmed ex-type strains of six Protomyces species (Table 1) were obtained from the USDA ARS culture collection (NRRL; https://nrrl.ncaur.usda.gov/). Species and strains used are: Protomyces arabidopsidicola sp. nov. strains C29, C2-11, and C2-15; P. gravidus strain Y-17093; P. inouyei strain YB-4354; $P$. inundatus strain Y-6349; P. lactucaedebilis strain YB-4353; P. macrosporus strain Y-1287; P. pachydermus strain YB-4355. The isolation of the culture $P$. arabidopsidicola strains $\mathrm{C} 29, \mathrm{C} 2-11$, and $\mathrm{C} 2-15$, from the leaf surface of healthy wild-growing Arabidopsis thaliana, in Helsinki, Finland, was described by Wang et al. (2016). Culture conditions, DNA extraction, PCR amplification, and DNA sequencing, were as described elsewhere (Wang et al. 2019; Wang et al. 2016). Average nucleotide identity (ANI) and average amino-acid identity (AAI) values of Protomyces genomes or proteomes were calculated using the online tool 
ANI/AAI-Matrix (Rodriguez-R and Konstantinidis 2016). Percent nucleotide identity of nrDNA and protein coding phylogenetic marker genes was determined using pairwise BLASTn (megablast) alignments using the multiple alignment tool at NCBI (National Center for Biotechnology Information; www.ncbi.nlm.nih.gov). Marker gene sequences for all species are available using the accession numbers listed below. Growth assays at low temperature were previously reported in Wang et al. (2019). Yeast cell size and morphological characterization was conducted by photographing three-day-old or two-week-old cultures with a LEICA 2500 microscope (www.leica-microsystems.com) or two-week-old colonies with a LEICA MZ10F stereo microscope. Cells and colonies were cultivated on YPG (yeast-extract, peptone, glucose). For cell size measurements, yeast cells were mounted on a slide in water for examination. Cell length and width were measured from photomicrographs with imageJ software (https://imagej.nih.gov/ij/). Carbon assimilation patterns among seven species were tested with API $50 \mathrm{CH}$ strips (bioMerieux SA; www.biomerieux.com) cultured at $21^{\circ} \mathrm{C}$ for $7 \mathrm{~d}$, according to the manufacturer's instructions.

The genome sequences and annotations of Saitoella complicata Saico1, Saccharomyces cerevisiae GCF000146045.2 R64, Schizosaccharomyces pombe GCF000002945.1, Pneumocystis murina B123, Taphrina populina JCM22190, and Neolecta irregularis DAH-3 were downloaded from NCBI (www. ncbi.nlm.nih.gov/). The phylogenetic tree with species representing Taphrinomycotina classes Neolectomycetes, Pneumocystidomycetes, Schizosaccharomycetes, and Taphrinomycetes was built with 636 single-copy protein sequences from genome annotations. Saccharomyces cerevisiae, representing Saccharomycotina, was utilized as an outgroup. Conserved single-copy protein sequences were identified with orthofinder (Emms and Kelly 2015). Alignment quality was controlled by applying sequence scores $>=0.8$ in MAFFT analysis with Guidance2 (Sela et al. 2015). Multiple sequences were concatenated with FASconCAT_V1.0 (Kück and Meusemann 2010). The randomized axelerated maximum likelihood method RAxML (Stamatakis 2014) and rapid bootstrapping (100x) (Stamatakis 2014) were employed for building the genome-wide tree, and (1000x) for nuclear DNA marker trees. Phylogenetic trees using the nuclear DNA markers; actin1 (act1), second largest subunit of RNA polymerase II (rbp2), large subunit of RNA polymerase II (rbp1), transcription elongation factor 1 (tef1) and tubulin beta chain (tub2) were aligned by ClustalX2.1 (Larkin et al. 2007). Sequences of DNA marker gene orthologs in Protomyces and Taphrina were discovered using local BLAST searches of their genomes using Schizosaccharomyces sequences as query. All phylogenetic trees were viewed and edited with iTOL (Letunic and Bork 2016). Trees based on the Bayesian inference method were constructed utilizing the MrBayes software package (Ronquist et al. 2012), selecting the general time reversible model and invgamma. Two independent analyses were started simultaneously with 10 , 000 generations and four chains set for the analysis run.

The sequences of proteins known to be involved in carbohydrate utilization in model yeast species were collected from NCBI and UniProt (https://www.uniprot.org/ ). Characterized protein sequences of key enzymes were selected as query sequences. Sequences used as search queries are listed in Supplementary File 2. A local installation of BLASTp was applied for searching enzyme hits in Protomyces genomes. Selection criteria are E value $<1 \mathrm{e}^{-30}$ and protein hits were manually curated to avoid duplicates. All analyses above were performed using CSC (https://www.csc.fi/) computing resources in Linux.

\section{RESULTS}

\section{Evidence of the new Protomyces species}

We previously isolated a novel Protomyces strain, strain C29, from the phylloplane of healthy individuals of thale cress (Arabidopsis thaliana) (Wang et al. 2016) growing in the wild in Helsinki, Finland. The strain C29, a member of operational taxonomic unit1 (OTU1), was identified as belonging to the genus Protomyces by BLAST searches with ITS sequences (Genbank acc. LT602858) showing the highest similarity (96\%) to P. inouyei (Wang et al. 2016). Two other identical strains (C2-11 and SC2-15) belonging to OTU1 based on identical ITS sequences where also isolated. One additional strain (strain A14) belonging to the genus Protomyces in OTU2, with an ITS sequence (Genbank acc. LT602859) similar but not identical to OTU1, was isolated from a distinct sample, giving four strains from two independent Arabidopsis individuals from two distinct locations within the common sampling area (Wang et al. 2016). The genome of the new species, named as $P$. arabidopsidicola below, and the genomes of six other Protomyces species were previously sequenced and subjected to comparative analysis (Wang et al. 2019). These six sequenced species represent all of the Protomyces species for which strains are currently available in culture collections (Table 1). All sequenced Protomyces species have small genome sizes (11.5-14.1 Mbp) with 50.9-52.8\% GC content. Our previous work (Wang et al. 2019) focused on the ecology of $P$. arabidopsidicola, its interactions with Arabidopsis, and comparison of the features of the seven sequenced genomes. Here we focus on the description and naming of the novel species as well as the phylogenetic implications of our Protomyces genome sequencing results (Wang et al. 2019).

In Fig. 1, the typical peat moss and stone environmental conditions of sites where Arabidopsis samples were collected for isolation is shown (Fig. 1a) as well as a representative individual of the healthy Arabidopsis plants collected in their native habitat (Fig. 1b). Yeast cell sizes (Table 2) as well as cell and colony morphology (Fig. 2) of all seven Protomyces species were analysed, where the cell size of $P$. 
arabidopsidicola was significantly shorter than its closest relative $P$. inouyei, suggesting it is a distinct species.

In order to reveal the evolutionary relationships and species delimitation within the genus, we built phylogenetic trees using various markers; specifically, DNA sequences of the nrDNA D1/D2 domain, the full ITS DNA sequences (ITS1-5S rDNA-ITS2), and conserved protein coding sequences from the genome sequencing data of $P$. arabidopsidicola and the other Protomyces species. All phylogenetic trees were constructed with the Maximum Likelihood (Fig. 3) and the Bayesian inference methods (Supplemental Fig. 1), which both yielded similar results and support the same

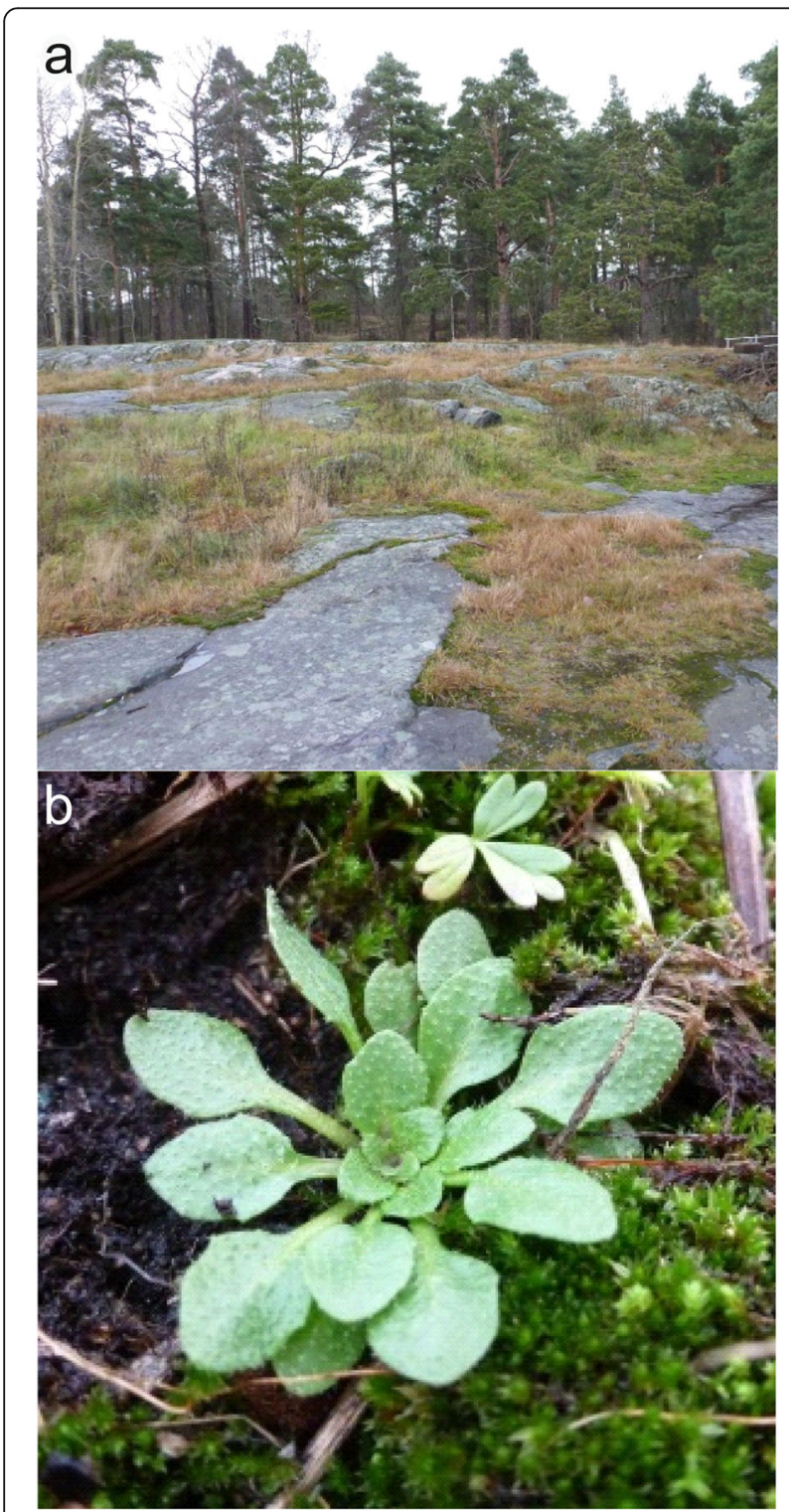

Fig. 1 Isolation environment and host. a The environment from which Protomyces arabidopsidicola sp. nov. was isolated. b A typical example of healthy wild thale cress (Arabidopsis thaliana) plants that were collected for yeast isolation conclusions. The ITS marker differentiated all strains at the species level, but with low support for some nodes (Fig. 3 a). D1/D2 trees offered poor species resolution and were poorly supported (Fig. 3 b). In order to quantitatively support the differences seen in these phylogenetic trees, we calculated the percent nucleotide identity between all the examined Protomyces species for the ITS and D1/D2 sequences (Table 3 a, b)

These results taken together suggest that the true diversity of the genus Protomyces is not captured or supported in the phylogenies utilizing the commonly used D1/D2 or ITS markers. Therefore, other methods are required to resolve the phylogeny of species in the genus. To this end, we utilized genome sequencing data and performed genome-wide phylogenetic analysis with the Maximum-Likelihood method using RAxML software (Stamatakis 2014) and the Bayesian inference method utilizing 1670 single-copy protein sequences that were common to these seven genomes. Clearly, $P$. arabidopsidicola occupies a unique position in a monophyletic clade with the six other Protomyces species, indicating it is a novel species of Protomyces most closely related to a clade composed of $P$. inouyei, $P$. lactucaedebilis, and $P$. pachydermus (Fig. 3, c). The percent identity of ITS marker genes also support that this is a new species (Table 3). As genomic sequencing is not practical for rapid species identification, we tested five nuclear genes $r b p 2$, tef1, rbp1, tub2, and act 1 as potential secondary lineage-specific phylogenetic DNA markers, both individually and together as a single concatenated sequence (Fig. 4). All of these nuclear DNA markers resolved $P$. arabidopsidicola as distinct from other Protomyces species analyzed, providing additional evidence at the DNA level that $P$. arabidopsidicola represents a novel species of Protomyces (Fig. 4). All markers performed reasonably well at resolving species in the genus (Fig. 4). However, only the act 1 tree topology closely resembled whole genome data, thus percent nucleotide identity for the act1 gene was calculated (Table $3 \mathrm{c}$ ).

In addition to phylogenetic analysis, comparisons of whole genome ANI and AAI between P. arabidopsidicola and the other six species were used as evidence to define species borders. ANI and AAI values were between 77.5 to $85.6 \%$ and 71.9 to $90.6 \%$, respectively (Table 4 ). The low levels of ANI $(\leq 95 \%)$ and AAI provide further evidence that $P$. arabidopsidicola is a new species distinct from the other six Protomyces species included.

Carbon assimilation profiles of $P$. arabidopsidicola and the other six Protomyces species were determined (Table 5). These data demonstrate that each species utilized a unique pattern of carbon sources. P. arabidopsidicola exhibited a distinct profile of carbon utilization traits, especially for D-cellobiose, amygdalin, L-arabinose and Darabinose (Table 5) further distinguishing it from P. inouyei. Based on this evidence, a new diagnostic key of seven species is provided below. Utilizing the genome annotations of seven 
Table 2 Yeast cell sizes

\begin{tabular}{|c|c|c|c|c|}
\hline Age & Species & Mean size \pm SD $(\mu \mathrm{m})$ & $\begin{array}{l}\text { Size range } \\
(\mu \mathrm{m})\end{array}$ & Reference $^{*}$ \\
\hline \multirow[t]{7}{*}{$3 d$} & P. arabidopsidicola & $4.8 \pm 1.6 \times 2.7 \pm 0.6$ & $2.0-12.4 \times 1.4-5.6$ & NA \\
\hline & P. gravidus & $5.2 \pm 1.3 \times 3.0 \pm 0.6$ & $2.7-9.6 \times 1.4-5.9$ & $2.5-10 \times 2.5-4$ \\
\hline & P. inouyei & $6.3 \pm 1.6 \times 2.6 \pm 0.4$ & $3.2-11.4 \times 1.5-4.2$ & $2.5-10 \times 2-4$ \\
\hline & P. inundates & $7.5 \pm 2.1 \times 3.8 \pm 0.6$ & $3.8-14.2 \times 1.1-5.4$ & $3.7-9 \times 2-4.7$ \\
\hline & P. lactucaedebilis & $5.4 \pm 1.5 \times 2.7 \pm 0.4$ & $3.0-10.8 \times 1.6-4.0$ & $3.5-9 \times 2.5-5$ \\
\hline & P. macrosporus & $5.2 \pm 1.6 \times 2.9 \pm 0.5$ & $2.3-13.0 \times 1.7-4.2$ & $3-7 \times 2.5-4$ \\
\hline & P. pachydermus & $7.4 \pm 2.1 \times 2.9 \pm 0.6$ & $3.6-13.6 \times 1.6-5.5$ & $3-8 \times 2.5-4$ \\
\hline \multirow[t]{7}{*}{$14 \mathrm{~d}$} & P. arabidopsidicola & $4.7 \pm 1.8 \times 2.6 \pm 0.8$ & $2.4-14.1 \times 1.6-5.7$ & NA \\
\hline & P. gravidus & $5.4 \pm 1.4 \times 2.6 \pm 0.5$ & $3.2-8.2 \times 1.4-3.8$ & \\
\hline & P. inouyei & $4.7 \pm 1.3 \times 2.7 \pm 1.1$ & $2.6-10.8 \times 1.1-6.5$ & \\
\hline & P. inundates & $8.7 \pm 3.8 \times 5.6 \pm 2.7$ & $3.6-18.7 \times 1.9-16.2$ & \\
\hline & P. lactucaedebilis & $5.2 \pm 1.5 \times 2.9 \pm 0.8$ & $2.8-9.7 \times 1.5-5.0$ & \\
\hline & P. macrosporus & $4.9 \pm 1.3 \times 2.7 \pm 1.0$ & $3.0-8.5 \times 1.6-8.1$ & \\
\hline & P. pachydermus & $6.4 \pm 2.6 \times 3.0 \pm 0.5$ & $3.8-20.8 \times 1.9-4.0$ & \\
\hline
\end{tabular}

Measurements were from $3 \mathrm{~d}$ and $14 \mathrm{~d}$ cells of Protomyces species. Yeast cells were cultured in YPG agar plates. Cell images were captured by LEICA 2500 microscope with a LEICA DFC490 camera. Cell length and width were measured with imageJ software. Two independent cultures were applied in the statistics, with around 100 cells sampled in each biological repeat. The yeast cells of $P$. arabidopsidicola had a significantly shorter length than its closest relative $P$. inouyei $(p<0.05)$ by one way ANOVA + Tukey HSD. NA: not available. "Reference*": is the published size range for each species according to Kurtzman (2011).

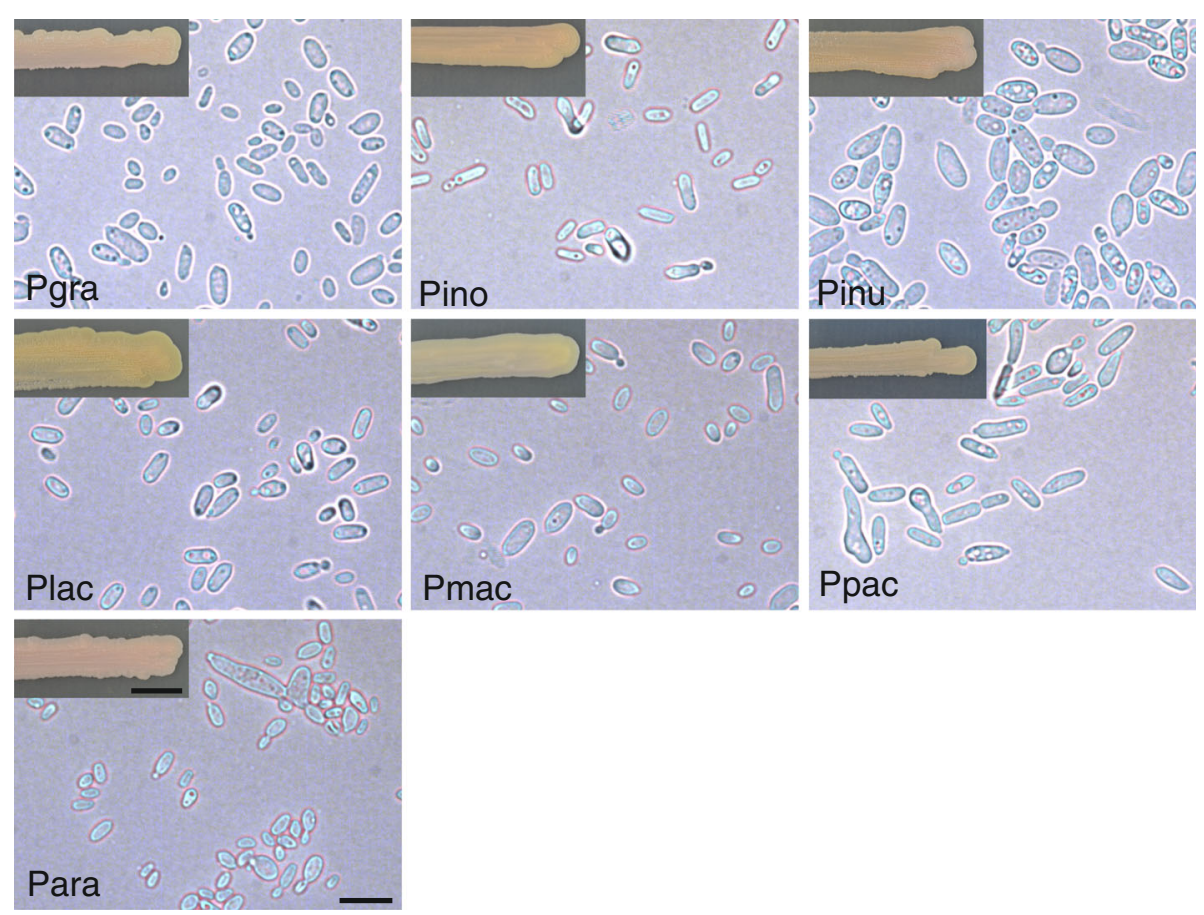

Fig. 2 Morphology of Protomyces species. Morphology of yeast cells and colonies of Protomyces species including Protomyces arabidopsidicola. Yeasts were cultured in YPG (peptone, yeast-extract, glucose) agar (2\%) medium. Photos of colonies taken 2 weeks after inoculation. Photos of cells were taken 3 days after inoculation. Pgra, P. gravidus; Pino, P. inouyei; Pinu, P. inundatus; Plac, P. lactucaedebilis; Pmac, P. macrosporus; Ppac, P. pachydermus; Para: P. arabidopsidicola. Scale bars, $10 \mu \mathrm{m}$ for yeast cells and $1 \mathrm{~cm}$ for colonies, are valid for all panels 

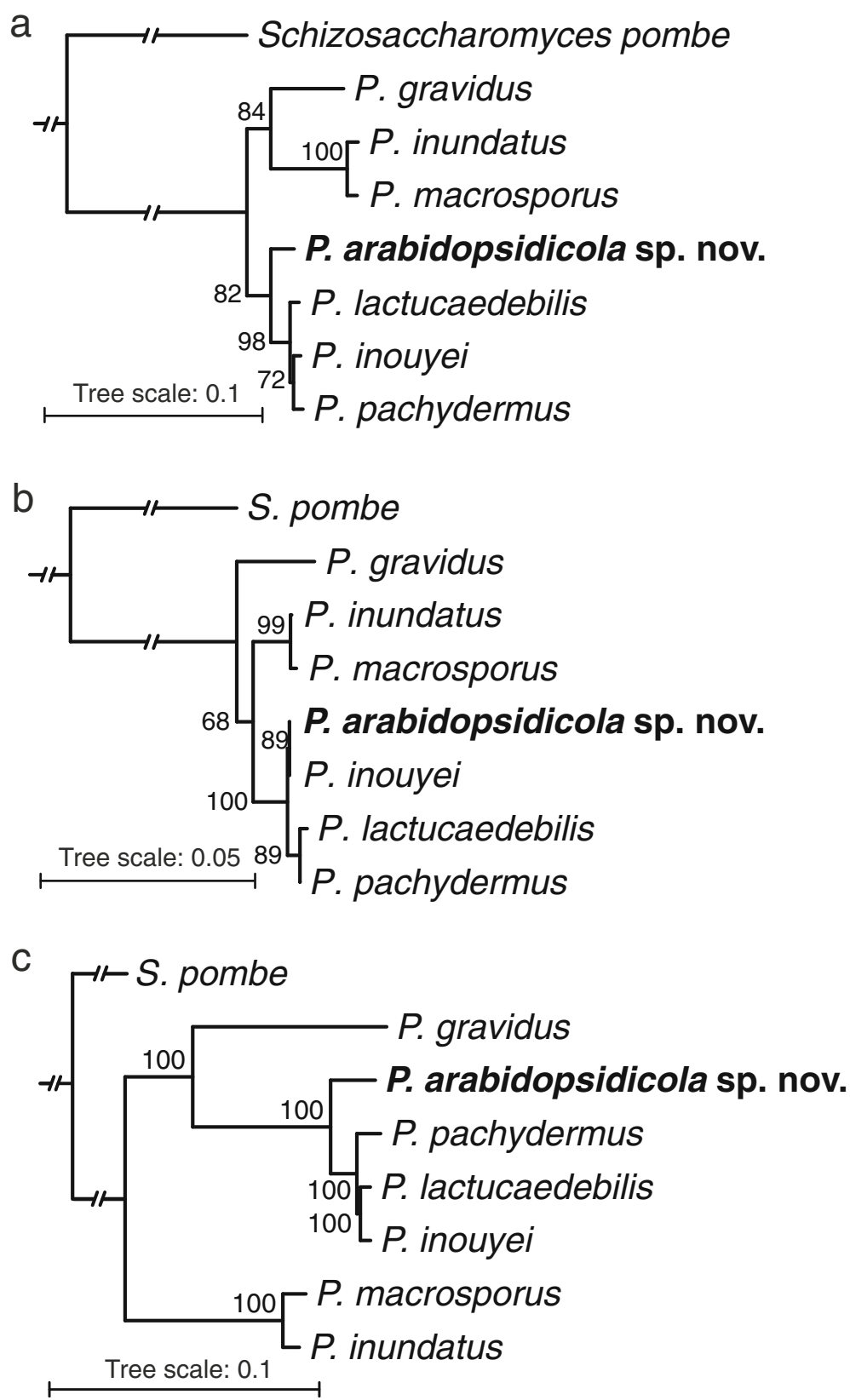

Fig. 3 Phylogenetic analysis of the genus Protomyces. Phylogenetic tree built by ITS (a), D1D2 (b) and genome-wide sequences (c), with maximum likelihood method. a ITS and $\mathbf{b}$ D1D2 sequences were aligned with ClustalX2. Bootstraping (1000x) was conducted and best-scoring ML tree were produced with randomized axelerated maximum likelihood (RAxML) rapid bootstrapping program. Bootstrap support values (\%) are indicated at each node. c RAxML with rapid bootstrapping (100x) were chosen for constructing the maximum likelihood tree utilizing 1670 concatenated single-copy conserved protein sequences from whole genome sequence data. Alignment quality control of single-copy conserved proteins was achieved by applying sequence scores $>=0.8$ in MAFFT analysis using Guidance2. Multiple aligned sequences of each species/strain were concatenated using FASconCAT_V1.0 and bootstrap values (\%) are indicated at the nodes. The output tre files were viewed with online tool iTOL. In all phylogenies Schizosaccharomyces pombe was used as an outgroup. For the same phylogenies built using the Bayesian inference method, see Supplemental Fig. 1

Protomyces species, we compared the presence of genes known to be involved in carbon source metabolism with selected metabolic traits (Fig. 5), including those that distinguish the Protomyces species in this study (Table 5). For some traits such as utilization of D-cellobiose, L-rhamnose,
D-ribose, and D-mannitol, the presence or absence of full pathways and the number of paralogs correlated with metabolic phenotypes (Fig. 5). However, for amygdalin, Larabinose, D-arabinose, and D-xylose, the genes encoding these enzymes were generally highly conserved and thus do 
Table 3 Percent nucleotide identity for three phylogenetic marker genes

\begin{tabular}{|c|c|c|c|c|c|c|c|}
\hline & Pinu & Pmac & Pgra & Plac & Pino & Ppac & Para \\
\hline \multicolumn{8}{|l|}{ (a) ITS } \\
\hline Pinu & 100 & & & & & & \\
\hline Pmac & 98.1 & 100 & & & & & \\
\hline Pgra & 90.3 & 89.8 & 100 & & & & \\
\hline Plac & 90.6 & 90.8 & 90.1 & 100 & & & \\
\hline Pino & 90.9 & 91.0 & 91.1 & 98.3 & 100 & & \\
\hline Рpac & 90.4 & 91.4 & 90.2 & 98.1 & 98.2 & 100 & \\
\hline Para & 91.7 & 91.7 & 90.8 & 95.7 & 96.2 & 95.5 & 100 \\
\hline \multicolumn{8}{|c|}{ (b) D1/D2 } \\
\hline Pinu & 100 & & & & & & \\
\hline Pmac & 99.8 & 100 & & & & & \\
\hline Pgra & 96.9 & 96.7 & 100 & & & & \\
\hline Plac & 97.6 & 97.4 & 96.2 & 100 & & & \\
\hline Pino & 97.9 & 97.7 & 96.2 & 99.7 & 100 & & \\
\hline Рpac & 97.7 & 97.6 & 96.4 & 99.5 & 99.5 & 100 & \\
\hline Para & 98.1 & 97.9 & 96.7 & 99.5 & 99.5 & 99.3 & 100 \\
\hline \multicolumn{8}{|l|}{ (c) Act1 } \\
\hline Pinu & 100 & & & & & & \\
\hline Pmac & 98.8 & 100 & & & & & \\
\hline Pgra & 87.4 & 86.8 & 100 & & & & \\
\hline Plac & 88.2 & 88.2 & 88.8 & 100 & & & \\
\hline Pino & 88.3 & 88.3 & 88.8 & 99.7 & 100 & & \\
\hline Рpac & 87.9 & 87.9 & 88.9 & 98.4 & 98.2 & 100 & \\
\hline Para & 87.6 & 87.8 & 88.0 & 95.7 & 96.7 & 95.1 & 100 \\
\hline
\end{tabular}

Percent nucleotide identity between Protomyces species determined by pairwise BLASTn (megablast) alignments for the ribosomal genes ITS (a) and D1/D2 (b), and the protein coding gene, Actin1 (Act1) (c). Species name abbreviations: Protomyces inundatus (Pinu), P. macrosporus (Pmac), P. gravidus (Pgra), P. lactucaedebilis (Plac), P. inouyei (Pino), P. pachydermus (Ppac), and P. arabidopsidicola (Para).

not correlate well with the inability of some species to utilize these carbon sources (Fig. 5).

\section{Phylogenomics}

The genus Protomyces resides within the Ascomycota subphylum Taphrinomycotina, class Taphrinomycetes, order Taphrinales, and family Protomycetaceae. The placement of the genus Protomyces has been problematic since its discovery. Relationships between genera are not well supported within the subphylum Taphrinomycotina (Kurtzman et al. 2011). Genome-wide phylogenetic trees constructed using both the Maximum-Likelihood (Fig. 6) and Bayesian inference (Supplemental Fig. 2) methods with concatenated single-copy conserved proteins from species representing each family within Taphrinomycotina were well supported. These confirmed the placement of Protomyces within this subphylum, as well as suggesting novel relationships between other genera within the subphylum.

\section{Protomyces inouyei and $P$. lactucaedebilis}

Previous treatments of Protomyces (Kurtzman 2011), which utilized the same six species we have sequenced and analyzed here, were unable to definitively conclude that these species were all genetically distinct. Our results (Table 4) clearly demonstrate that most are distinct species. However, the two species, $P$. inouyei and P. lactucaedebilis, may not be distinct given their $>96 \%$ ANI and $>97 \%$ AAI values at the whole genome level (Table 4). The evolutionary distance between them is small in the phylogenetic trees built with all makers tested (Figs. 3, 4, Table 3). Additionally, comparisons of genomic assemblies indicated a very high level of synteny between the genomes of $P$. inouyei and $P$. lactucaedebilis (Fig. 7). These data suggest that $P$. inouyei and P. lactucaedebilis may be strains of the same species, rather than distinct species.

\section{Dichotomous key to Protomyces species}

The diagnostic key is based on carbon assimilation patterns from D-adonitol, Methyl- $\alpha \mathrm{D}$-mannopyranoside, Larabinose, salicin, D-cellobiose and inulin.

The diagnostic key is based on carbon assimilation patterns from D-adonitol, Methyl- $\alpha \mathrm{D}$-mannopyranoside, L-arabinose, salicin, D-cellobiose and inulin.

\begin{tabular}{ll}
\hline D-adonitol is assimilated & $\boldsymbol{P}$. inouyei \\
D-adonitol is not assimilated & 2 \\
2 (1) Ethyl-aD-mannopyranoside is assimilated & $\boldsymbol{P}$. arabidopsidicola \\
Methyl-aD-mannopyranoside is not assimilated & 3 \\
3 (2) L-arabinose is assimilated & $\boldsymbol{P}$. lactucaedebilis \\
L-arabinose is not assimilated & 4 \\
4 (3) Salicin is assimilated & $\boldsymbol{P}$. gravidus \\
Salicin is not assimilated & 5 \\
5 (4) D-cellobiose is assimilated & $\boldsymbol{P}$. pachydermus \\
D-cellobiose is not assimilated & 6 \\
(5) Inulin is assimilated & $\boldsymbol{P}$. inundatus \\
Inulin is not assimilated & $\boldsymbol{P}$. macrosporus \\
\hline
\end{tabular}

\section{TAXONOMY}

Protomyces arabidopsidicola Kai Wang \& Overmyer, sp. nov.

MycoBank: MB 830646.

Etymology: The epithet refers to the host plant (Arabidopsis thaliana), from which the fungus was isolated ("the Arabidopsis-inhabiting Protomyces".)

Diagnosis: Molecularly differentiated from all other Protomyces species based on ITS and Actin1, but not D1/D2, gene sequences. Physiologically differentiated 


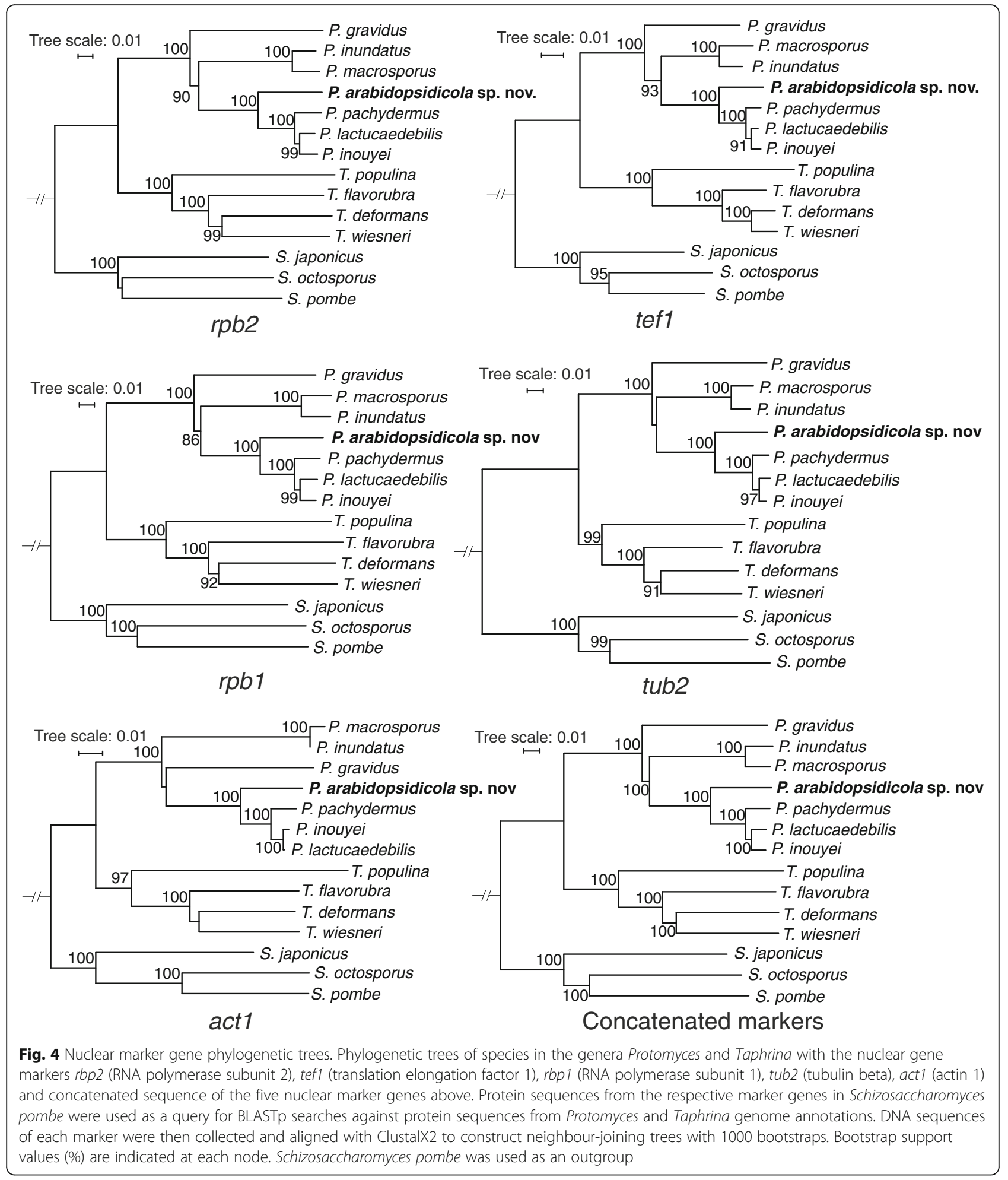

from $P$. inouyei based on its inability to utilize $\mathrm{D}$ adonitol, D-lyxose, inulin, inositol, L-rhamnose, or Larabitol. Further differentiated from other Protomyces species (P. gravidus, $P$. inundatus, $P$. lactucaedebilis, $P$. macrosporus, and $P$. pachydermus) by its ability to utilize methyl- $\alpha$-D-mannopyranoside. Morphologically differentiated based on the shorter $(4.8 \pm 1.6 \mu \mathrm{m})$ mean length of $3 \mathrm{~d}$ old yeast cells in culture on YPD medium compared to $P$. inouyei $(6.3 \pm 1.6 \mu \mathrm{m})$. 
Table $4 \mathrm{ANI}$ and AAI values between Protomyces species genomes

\begin{tabular}{llllllll}
\hline & Pinu & Pmac & Pgra & Plac & Pino & Ppac & Para \\
\hline Pinu & - & 94.7 & 71.4 & 71.9 & 71.8 & 71.9 & 72.0 \\
Pmac & $\mathbf{9 2 . 0}$ & - & 71.3 & 71.8 & 71.7 & 71.9 & 71.9 \\
Pgra & $\mathbf{7 7 . 9}$ & $\mathbf{7 7 . 8}$ & - & 74.2 & 74.1 & 74.1 & 74.2 \\
Plac & $\mathbf{7 8 . 0}$ & $\mathbf{7 8 . 3}$ & $\mathbf{7 7 . 6}$ & - & 97.3 & 95.6 & 90.6 \\
Pino & $\mathbf{7 8 . 0}$ & $\mathbf{7 7 . 9}$ & $\mathbf{7 7 . 6}$ & $\mathbf{9 6 . 0}$ & - & 95.6 & 90.6 \\
Ppac & $\mathbf{7 8 . 0}$ & $\mathbf{7 7 . 8}$ & $\mathbf{7 7 . 5}$ & $\mathbf{9 3 . 6}$ & $\mathbf{9 3 . 6}$ & - & 90.1 \\
Para & $\mathbf{7 7 . 9}$ & $\mathbf{7 8 . 1}$ & $\mathbf{7 7 . 5}$ & $\mathbf{8 5 . 6}$ & $\mathbf{8 5 . 5}$ & $\mathbf{8 5 . 0}$ & -
\end{tabular}

ANI (average nucleotide identity) and AAI (average amino-acid identity) values among Protomyces species. Genome and annotation matrix were applied with online tool ANI/AAl-Matrix using data from (Wang et al. 2019). The lower matrix shows the ANI values (in bold) and the upper matrix indicates the AAI values (in plain text). Species name abbreviations: Protomyces inundatus (Pinu), P. macrosporus (Pmac), P. gravidus (Pgra), P. lactucaedebilis (Plac), P. inouyei (Pino), P. pachydermus (Ppac), and P. arabidopsidicola (Para).

Type: Finland: Helsinki, $60.23270{ }^{\circ} \mathrm{N} 25.06191{ }^{\circ} \mathrm{E}$, isol, ex leaf wash of healthy wild growing thale cress (Arabidopsis thaliana), May 2013, K. Wang \& K. Overmyer, strain C29 (HAMBI 3697 - holotype preserved in a metabolically inactive state; DSM 110145 - ex-holotype culture). ITS sequence, Genebank LT602858.

Description: Haploid cells yeast-like, oval $2.0-12.4 \times$ $1.4-5.6 \mu \mathrm{m}$ when cultured on YPG for $3 \mathrm{~d}$ at $21^{\circ} \mathrm{C}$ (Fig. 8). Single colonies circular, convex, yellowish becoming slightly pinkish after about a week (Fig. 8, inset). Growth does not occur over $30^{\circ} \mathrm{C}$ or below $8^{\circ} \mathrm{C}$ on YPG agar medium for $7 \mathrm{~d}$; slow growth with colony appearance at $\geq 2$ weeks observed at $4{ }^{\circ} \mathrm{C}$. Carbon source utilization Yeast-like cells can assimilate glycerol, Dxylose, D-glucose, D-fructose, D-mannose, D-mannitol, D-sorbitol, amygdalin, arbutin, esculin ferric citrate, salicin, D-cellobiose, D-maltose, D-saccharose (sucrose), Dtrehalose, D-raffinose, amidon (starch), xylitol, gentiobiose, D-turanose, D-arabitol, and weakly growth with D-arabinose, L-arabinose, Methyl- $\alpha$-D-mannopyranoside, Methyl- $\alpha$-D-glucopranoside, D-melezitose, Potassium 2-ketogluconate, but do not assimilate erythritol, D-ribose, L-xylose, D-adonitol, Methyl- $\beta$-D-xylopyranoside, D-galactose, L-sorbose, L-rhamnose, dulcitol, inositol, $\mathrm{N}$-acetylglucosamine, D-lactose, D-melibiose, inulin, glycogen, D-lyxose, D-tagatose, D-fucose, L-fucose, Larabitol, potassium gluconate or potassium 5ketogluconate.

Notes: The genome size of Protomyces arabidopsidicola is $11.9 \mathrm{Mbp}$ (50.9\% GC content), with 5514 annotated protein-coding genes (Wang et al. 2019).

Additional material examined: Finland: Helsinki, $60.23270{ }^{\circ} \mathrm{N} 25.06191{ }^{\circ} \mathrm{E}$, isol, ex leaf wash of healthy wild growing thale cress (Arabidopsis thaliana), May 2013, K. Wang \& K. Overmyer strains C2-11(HAMBI $3736=$ DSM 111894) and C2-15 (HAMBI $3737=$ DSM 111895).

\section{DISCUSSION}

\section{Recognition of Protomyces arabidopsidicola}

$P$. arabidopsidicola is recognized based on the phylogenetic data (Figs. 3, 4, and Wang et al. 2019) physiological characters (Fig. 2, Tables 2 and 4), its association with Arabidopsis (Agler et al. 2016; Wang et al. 2019), and the low ANI and AAI values between $P$. arabidopsidicola and other known Protomyces species (Table 4). This was isolated in an effort to establish experimental systems to study the genetics of plant/yeast interactions using the genetic model plant Arabidopsis, for which associated yeasts were previously few to unknown (Wang et al. 2016, 2019). We obtained three strains with identical ITS sequences, further justified by the strength of the whole genome phylogenetic data, and further the novelty of this species that interacts with a plant widely outside the known host range of other Protomyces species. The strength of the data supporting its association with Arabidopsis (Agler et al. 2016; Wang et al. 2016; Wang et al. 2019), demonstrates the need for further research on this grossly understudied genus.

Previous phylogenetic analysis of Protomyces species used the host tissue, in which ascogenous cells were formed, as characteristic for their classification. Further, morphology and cell size comparisons were typically done with both the ascogenous cells, which only exist during natural host infection, and cultured yeast phase cells. For reasons discussed below, $P$. arabidopsidicola strain C29 was not expected to cause disease. In the absence of infected host tissue, it was not possible to obtain ascogenous cells; thus only yeast cell sizes were compared to the six available Protomyces species. Our measurements of yeast cell sizes in the other Protomyces species (Table 2) were in agreement with previously published size ranges (Kurtzman 2011).

The application of molecular tools has extensively widened our knowledge of fungal diversity and phylogeny (Blackwell 2011; Crous et al. 2015; Rosling et al. 2011). Our results (Fig. 3 a-b) suggest that the true diversity of the genus Protomyces is not captured or supported in the D1/D2 or ITS phylogenies. Similar results were obtained in analyses using a different set of species in our previous work (Wang et al. 2019). Also, the same conclusion has been made previously in the sister genus Taphrina (Rodrigues and Fonseca 2003). Our full genome based phylogenetic tree resolved all species and was well supported (Fig. 3c), but is not practical for the rapid identification of Protomyces species. Five single gene nuclear markers, as used by Stielow et al. (2015), performed 
Table 5 Carbon assimilation patterns of Protomyces species

\begin{tabular}{|c|c|c|c|c|c|c|c|}
\hline Carbon source & Pgra & Pino & Pinu & Plac & Pmac & Ppac & Para \\
\hline Glycerol & + & + & + & + & + & + & + \\
\hline Erythritol & - & - & - & - & - & - & - \\
\hline D-Arabinose & - & + & + & w & + & + & w \\
\hline L-Arabinose & - & + & - & w & - & - & w \\
\hline D-Ribose & - & - & - & - & - & - & - \\
\hline D-Xylose & + & + & + & w & + & w & + \\
\hline L- Xylose & - & - & - & - & - & - & - \\
\hline D-Adonitol & - & + & - & - & - & - & - \\
\hline Methyl- $\beta D$ - xylopyranoside & - & - & - & - & - & - & - \\
\hline D-Galactose & - & - & - & - & - & - & - \\
\hline D-Glucose & + & + & + & + & + & + & + \\
\hline D-Fructose & + & + & + & + & + & + & + \\
\hline D-Mannose & + & + & + & + & + & + & + \\
\hline L-Sorbose & - & - & - & - & - & - & - \\
\hline L-Rhamnose & - & + & - & - & - & - & - \\
\hline Dulcitol & - & - & - & - & - & - & - \\
\hline Inositol & - & + & - & - & - & - & - \\
\hline D-Mannitol & + & + & + & + & + & + & + \\
\hline D-Sorbitol & - & w & - & + & w & w & + \\
\hline Methyl-aD-Mannopyranoside & - & + & - & - & - & - & w \\
\hline Methyl-aD-Glucopranoside & - & w & + & + & - & w & w \\
\hline N-Acetylglucosamine & - & + & - & - & - & - & - \\
\hline Amygdalin & w & w & - & - & - & - & + \\
\hline Arbutin & w & + & - & - & - & - & + \\
\hline Esculin ferric citrate & + & + & - & + & - & - & + \\
\hline Salicin & w & + & - & - & - & - & + \\
\hline D-Cellobiose & + & + & - & + & - & w & + \\
\hline D-Maltose & + & + & + & + & + & + & + \\
\hline D-Lactose & - & - & - & - & - & - & - \\
\hline D-Melibiose & - & - & - & - & - & - & - \\
\hline D-Saccharose (sucrose) & + & + & + & + & + & + & + \\
\hline D-Trehalose & + & + & + & + & + & + & + \\
\hline Inulin & + & + & + & + & - & w & - \\
\hline D-Melezitose & + & + & + & + & + & + & w \\
\hline D-Raffinose & + & + & + & + & + & + & + \\
\hline Amidon (starch) & + & + & + & + & + & + & + \\
\hline Glycogen & w & - & + & - & - & w & - \\
\hline Xylitol & w & + & + & + & + & + & + \\
\hline Gentiobiose & + & + & - & + & - & - & + \\
\hline D-Turanose & + & + & + & + & + & + & + \\
\hline D-Lyxose & w & w & + & - & + & w & - \\
\hline D-Tagatose & - & - & - & - & - & - & - \\
\hline D-Fucose & - & - & - & - & - & - & - \\
\hline L-Fucose & - & - & - & - & - & - & - \\
\hline
\end{tabular}


Table 5 Carbon assimilation patterns of Protomyces species (Continued)

\begin{tabular}{lllllll}
\hline Carbon source & Pgra & Pino & Pinu & Plac & Pmac & Ppac \\
\hline D-Arabitol & + & + & - & + & + & + \\
L-Arabitol & w & w & + & - & - & - \\
Potassium gluconate & - & - & - & - & - \\
Potassium 2-Ketogluconate & w & + & - & w & - & - \\
Potassium 5-Ketogluconate & - & - & - & - & w \\
\hline
\end{tabular}

Carbon assimilation was tested using $50 \mathrm{CH}$ strips (biomerieuxdirect.com). Key to growth symbols: + , positive, w, weakly positive,,- , negative. Abbreviations: Pgra, P. gravidus; Pino, P. inouyei; Pinu, P. inundatus; Plac, P. lactucaedebilis; Pmac, P. macrosporus; Ppac, P. pachydermus; Para, P. arabidopsidicola. Carbon sources listed in bold text are used differentially by these Protomyces species

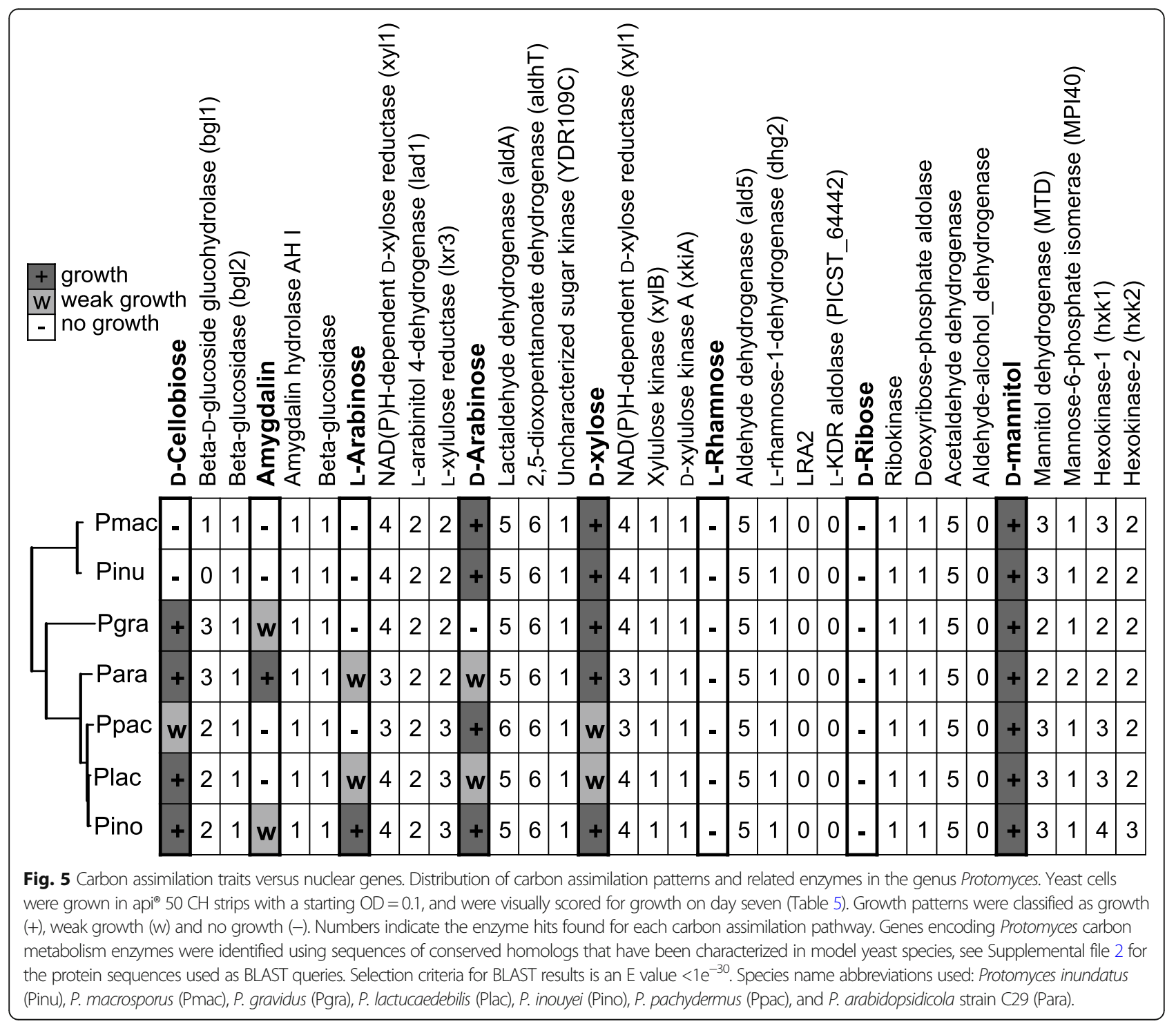




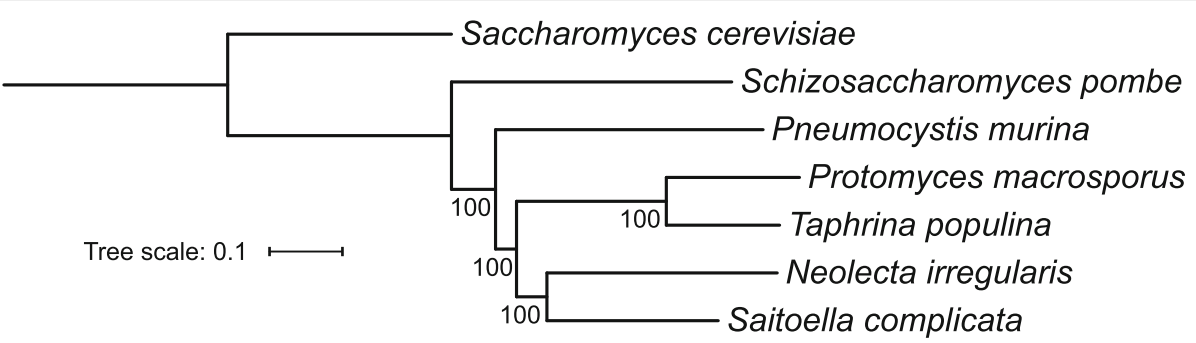

Fig. 6 Phylogeny of the subphylum Taphrinomycotina. Maximum likelihood phylogenetic tree of representative species in the subphylum Taphrinomycotina. Tree was built using 636 single-copy protein sequences that were common to all species used. Alignment quality control of single-copy conserved proteins was achieved by applying sequence scores $>=0.8$ in MAFFT analysis using Guidance2. Saccharomyces cerevisiae was used as an outgroup. Multiple aligned sequences of each species were concatenated into a single long sequence using FASconCAT_V1.0. The randomized axelerated maximum likelihood method (RAxML) and rapid Bootstrapping (100x) were applied for constructing the maximumlikelihood phylogenetic tree. Bootstrap support values (\%) are shown at each node. The output files were viewed with online tool iTOL. For the same phylogeny built using the Bayesian inference method, see Supplemental Fig. 2

reasonably well at species resolution, and one marker, act1, exhibited the same architecture as the phylogenetic tree constructed with genome-wide concatenated protein data (Figs. 3c, 4). Further studies will be required to test how robust act1 is in mimicking the topology of the genome wide tree when other species are added. However, as act1 is a commonly used marker, we propose that once a new strain has been placed in Protomyces by ITS or D1/D2 sequencing, the act1 gene sequence can be used as a secondary marker for species identification.

Carbon source utilization remains a useful tool for rapid species identification (Kurtzman et al. 2011), especially in a genus such as Protomyces, with a wealth of older literature and little molecular data available for comparison. Generally, the molecular underpinnings of carbon assimilation remain understudied. The availability of whole genome sequencing data offers an opportunity to correlate genomic carbon metabolism gene content with metabolic traits. Our data indicate that some traits correlate well with genomic content, while others do not (Fig. 5). A similar finding has been previously reported for D-xylose in a wider sampling of yeast species (Riley et al. 2016). The reasons for these differences remain unknown but this may account for discrepancies in carbon use traits observed between different labs or variable results seen within a single lab.

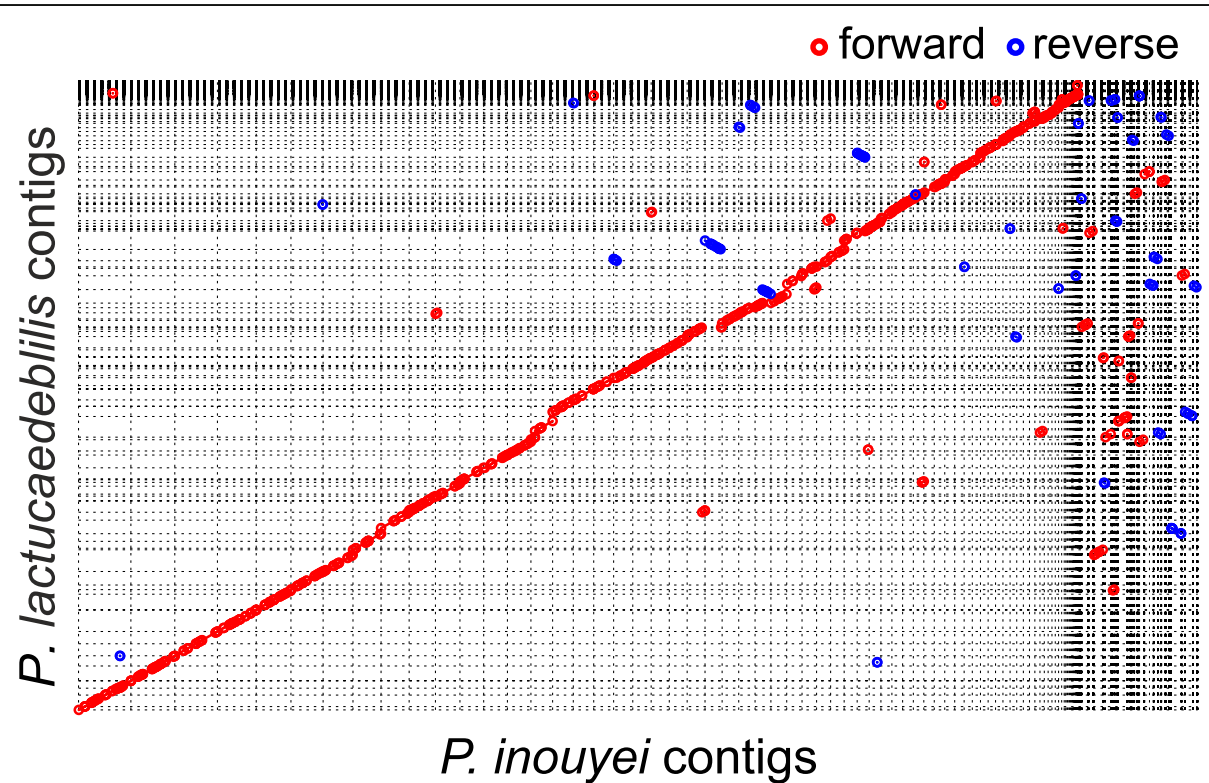

Fig. 7 Genome synteny of Protomyces inouyei and P. lactucaedebilis. Dot-plots of whole genome alignment between Protomyces inouyei and $P$. lactucaedebilis contigs. Mummer 4.0 .0 beta2 (nucmer) was applied for genome assembly comparison with default settings. Forward alignment is shown in red and reverse alignment in blue. Optimal co-linear order of contigs was shaped with mummerplot (parameter --fat). Mummerplot output ps files were viewed and edited with CorelDraw 2018 


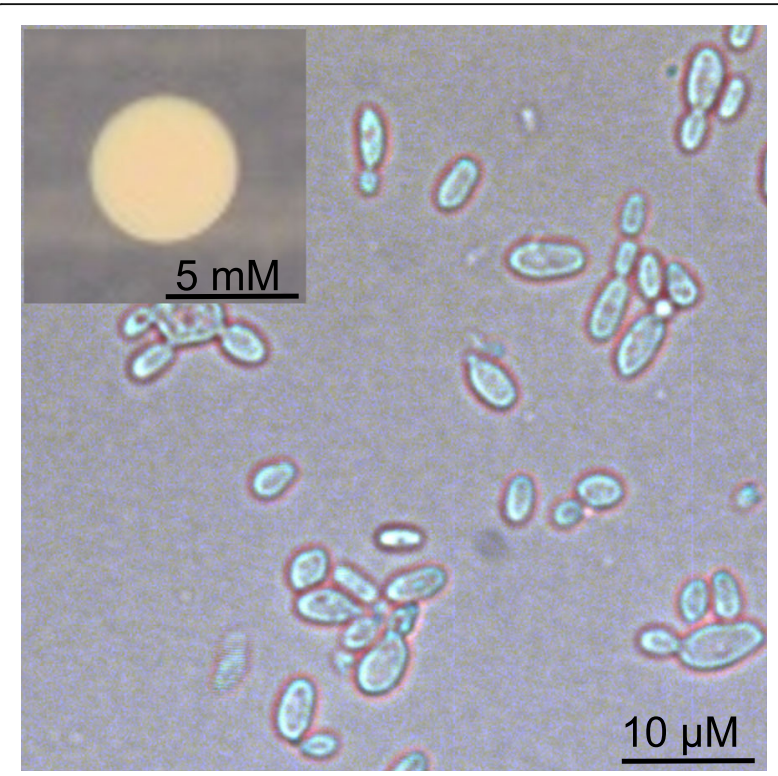

Fig. 8 The morphology of Protomyces arabidopsidicola sp. nov. type strain C29. Photo plate depicts the micro-morphology of the yeast phase and the macro-morphology a colony solid agar plate (insert). In both photos cultivation was on YPG (yeast-extract, peptone, glucose) medium for 1 week (colony) and 3 days (yeast cells)

Differences in the expression or conditional expression of carbon utilization genes may account for this; such latent metabolic capability has been previously suggested in a study using a wide selection of different yeasts of biotechnological interest (Riley et al. 2016).

\section{The association of Protomyces with Arabidopsis thaliana}

Arabidopsis is very distantly related to the typical Protomyces hosts. Thus, we sought multiple lines of evidence to support the validity of the ProtomycesArabidopsis association. In addition to our multiple isolations (Wang et al. 2016), Protomyces OTUs were also found over multiple years in two separate cities in Germany (Wang et al. 2019; Agler et al. 2016). Recently, Protomyces, or higher level phylogenetic classifications that include Protomyces, have been reported in other Arabidopsis phyllosphere microbiome studies (Brachi et al., 2017; Regalado et al. 2020).

All previously examined Protomyces species are heterothallic (Kurtzman 2011) and thus require conjugation with a partner of the opposite mating type prior to transitioning into the pathogenic hyphal form. Protomyces MAT loci analysis (Wang et al. 2019) confirmed heterothallism; all Protomyces species except one had a single MAT locus with either matPi/matPc or matMi/matMc. Exceptionally, P. inundatus had two MAT loci, one bearing matPi/matPc and the other matMi/matMc, suggesting homothallism in this species (Wang et al. 2019). As strain C29 has a single mat locus bearing only matPi/matPc it is not expected to be pathogenic without another strain bearing matMi/ matMc. We confirmed the lack of pathogenicity in Arabidopsis infection experiments under a wide variety of conditions, including growth chamber experiments and overwinter field experiments, which revealed no disease symptoms (Wang et al. 2019). $P$. arabidopsidicola was then used to explore the role of phyllosphere residency in the Protomyces life-cycle. The species persisted in the Arabidopsis phylloplane of both sterile in vitro grown and soil grown plants, while titres of its closest relative $P$. inouyei rapidly decreased (Wang et al. 2019). Furthermore, P. arabidopsidicola was reisolated from Arabidopsis after overwintering for 6 months in field infection experiments (Wang et al. 2019). ITS metagenomics experiments have revealed Protomyces strains on the leaf surface of other plants that are not members of either Compositae or Umbelliferae (Wang et al. 2016; Prior et al. 2017; Wang et al. 2019). This suggests that Protomyces may exploit Arabidopsis and possibly also multiple other alternate hosts as a phyllosphere resident. We cannot at this time exclude the possibilities that $P$. arabidopsidicola is pathogenic on Arabidopsis or a different currently unknown host species. The collection of more strains of Protomyces from Arabidopsis and additional experimental evidence will be necessary for a deeper understanding of the ecology of the species.

Finally, comparative genomic analysis revealed the genomic signatures in $P$. arabidopsidicola consistent with a host jump or life-style change leading us to hypothesize that this fungus may have recently jumped hosts (Wang et al. 2019). Taken together, these data support the species being associated with Arabidopsis, whose phylloplane it can utilize as a growth space, as a possible host, or alternate host.

\section{Protomyces is not strictly related to hosts in Compositae or Umbelliferae}

The genus Protomyces has been narrowly defined based on the following key criteria; morphological characteristics, host plant phylogeny, and their localization with the tissues of the host (Reddy and Kramer 1975; Kurtzman 2011). Currently all Protomyces species are known to be plant pathogens, infecting hosts in only two plant families. Previously, many yeasts have been excluded from Protomyces based on their atypical cell sizes and association with hosts in other plant families (Reddy and Kramer 1975). Our results placed $P$. arabidopsidicola as a district species within Protomyces and is associated with the Arabidopsis phylloplane, prompting us to propose the species name "arabidopsidicola". These results indicate that the genus Protomyces may include species with a nonpathogenic phyllosphere resident life-style on alternate 
hosts and/or those associated with hosts outside Umbelliferae and Compositae, i.e. species that do not adhere to the narrow criteria previously used to define the genus. The isolation and characterization of $P$. arabidopsidicola as well as the identification of OTUs that belong to Protomyces based on their ITS sequence and reside on other plant families (Wang et al. 2019) both support this view. However, as stated above, we cannot at this time exclude the possibility that $P$. arabidopsidicola is pathogenic on a host that is currently unknown. Nonetheless, the occurrence of a Protomyces species in the phylloplane of a host species outside of the usual host range is novel. This suggests that Protomyces species may also survive via the utilization of the phylloplane of alternate hosts. Further studies will be required to fully resolve this issue, however, we propose here that the definition of the genus Protomyces be broadened to allow species with a phylloplane resident lifestyle and also species associated with hosts outside of Umbelliferae (Apiaceae) and Compositae (Asteraceae).

\section{Phylogenetic implications of Protomyces species genome sequencing}

Phylogenomics with 636 conserved single copy concatenated nuclear encoded proteins confirmed the placement of Protomyces within Taphrinomycotina (Fig. 6, Supplemental Fig. 2). However, our data place both Saitoella and Neolecta in a sister clade to that of Taphrina and Protomyces suggesting that Saitoella is outside the family Protomycetaceae and order Taphrinales, where it was previously assigned (Sugiyama et al. 2006). This suggests that Saitoella should either define its own family to be created and named or that this genus should be assigned to Neolectales. Pneumocystis, representative of the Pneumocystidales, was previously a sister group with Schizosaccharomyces, but our results now suggest it may reside as an outgroup between Taphrinales and Schizosaccharomycetales. Further studies with a wider selection of representative species will be required to better resolve the relationships within the subphylum Taphrinomycotina.

Our results and those of many others (Liu et al. 2009; Rosling et al. 2011) suggest there are a large number of undiscovered and lost species in Taphrinomycotina, whose discovery and analysis would aid in resolving the relationships in this fascinating subphylum. The family Protomycetaceae now contains the genera Burenia, Protomyces, Protomycopsis, Saitoella, Taphridium, and Volkartia. The borders between these genera also remain poorly defined and all but Saitoella have similar plant pathogenic life-styles. Unfortunately, with the exception of the genera Protomyces and Saitoella, strains and DNA sequences are not available for species in any of these genera.
Kurtzman (2011) concluded that his previous treatment of six Protomyces species, including P. inouyei and $P$. lactucaedebilis, could not conclude that all were distinct species. Our genomic data (Figs. 3, 4, 7, Tables 3, 4), suggest that $P$. inouyei and $P$. lactucaedebilis may be two strains of the same species. Phylogenies constructed with ITS and D1D2 sequences were either not well supported or did not resolve at the species level within the genus Protomyces (Fig. 3a-b). The ITS percent identity value between $P$. inouye $i$ and $P$. lactucaedebilis was $98.3 \%$ (Table 3a), just under the 98.4\% threshold for species delimitation (Vu et al. 2016). D1D2 percent identity values exceeded the 99.5\% threshold for species delimitation ( $\mathrm{Vu}$ et al. 2016) in several instances, including comparisons of clearly distinct species (Table $3 \mathrm{~b}$ ). The strongest evidence for merging $P$. inouyei and P. lactucaedebilis comes from whole genome phylogeny and ANI data (Fig. 3c; Table 4). Their ANI value exceeds the common border of $95 \%$ used for prokaryotes (Konstantinidis and Tiedje 2005; Goris et al. 2007). However, species delimitation borders using ANI and AAI values are not yet well established for yeasts and fungi, with limited data available. ANI values < $88 \%$ were reported between Rhizoctonia solani isolates from different anastomosis groups (Wibberg et al. 2015). In the same study, as a control ANI and AAI values were calculated for sequenced pairs of strains from five fungal species (Aspergillus niger, Candida albicans, Crytococcus neoformans, Fusarium oxysporum, and Metarhizium anisopliae), all of which were $97.42-99.97 \%$ for ANI and 98.11-99.98\% for AAI. The ANI threshold of 95\% in prokaryotes was originally justified based on its correspondence with the similarity index threshold of $70 \%$, determined by DNA-DNA hybridization, a longused standard for species delineation (Goris et al. 2007). A few fungal DNA-DNA hybridization studies have reported the same $70 \%$ similarity for Fusarium species (Kurtzman 1993b) suggesting the 95\% ANI value may also be relevant to fungi. However, we contend that further studies are needed.

We conclude that $P$. inouyei and P. lactucaedebilis may be conspecific, but further studies into the use of ANI and AAI values for species delimitation are required before this can be formally proposed. Additionally, studies into the host specificities of these Protomyces species may also help resolve this issue. Although $P$. inouyei and P. lactucaedebilis are thought to have distinct hosts, infecting Crepis species and Lactuca debilis, respectively (Table 1), this has never been formally tested by reciprocal infections. 


\section{CONCLUSIONS}

The Protomyces strain C29 isolated from the phylloplane of Arabidopsis is confirmed as a new species named here as $P$. arabidopsidicola. Given the novel life-style and the association of this new species with a plant species outside of the previously accepted host range of the members of the genus Protomyces, we propose that the definition of the genus be widened to include nonpathogenic phylloplane-resident species and species associated with hosts outside families Umbelliferae (Apiaceae) and Compositae (Asteraceae).

\section{Supplementary Information}

The online version contains supplementary material available at https://doi. org/10.1186/s43008-021-00054-2

Additional file 1: Supplemental Fig. 1. Phylogenetic analysis of the genus Protomyces. Phylogenetic trees built by ITS (a), D1D2 (b) and genome-wide sequences (c), with Bayesian method. Bayesian phylogenetic trees were produced by using program MrBayes version 3.2.7a. The input .nex files are generated from the aligned fasta files used in (Fig. 1). General time reversible model and invgamma were chosen. Two independent analyses were started simultaneously, and 10,000 generations and four chains were set for analysis run. Posterior probability (\%) support values are shown at each node. The output tre files were viewed with online tool iTOL. In all phylogenies Schizosaccharomyces pombe was used as an outgroup. Supplemental Fig. 2. Phylogeny of the subphylum Taphrinomycotina. Maximum likelihood phylogenetic tree of representative species in the subphylum Taphrinomycotina. Trees were built using 636 single-copy protein sequences that were common to all species used. Alignment quality control of single-copy conserved proteins was achieved by applying sequence scores $>=0.8$ in MAFFT analysis using Guidance2. Saccharomyces cerevisiae was used as an outgroup. Multiple aligned sequences of each species were concatenated into a single long sequence using FASconCAT_V1.0. Bayesian inference method results utilized the MrBayes software package. General time reversible model and invgamma were chosen. Two independent analyses were started simultaneously, and 10,000 generations and four chains were set for analysis run. Posterior probability (\%) support values are shown at each node. The output files were viewed with online tool iTOL. Supplemental file $\mathbf{1 .}$ Queried yeast culture collections, the file contains a list of the thirty major yeast culture collections that were queried for availability of strains for species belonging to the genus Protomyces. Supplemental file 2. Carbon utilization enzyme protein sequences, the file contains the characterized protein sequences from model yeast species that were used as BLAST queries against the genomes of Protomyces species to identify genes involved in the utilization of various carbon sources.

\section{Abbreviations \\ nrDNA: Nuclear ribosomal DNA; D1/D2: nrDNA 265 large-subunit D1/D2 do- main; ITS: nrDNA internal transcribed spacer; ANI: Average nucleotide similarity; AAI: Average amino acid similarity; YPG: Yeast-extract, peptone, glucose medium; act1: Actin1 gene; rbp2: Gene for the second largest subunit of RNA polymerase II; rbp 1: Gene for the large subunit of RNA polymerase II; tef1: Transcription elongation factor 1 gene; tub2: Tubulin beta chain gene; OTU: Operational taxonomic unit; HAMBI: University of Helsinki HAMBI Culture Collection; DSM: German Collection of Microorganisms and Cell Cultures GmbH; Para: Protomyces arabidopsidicola; Pgra: P. gravidus; Pino: P. inouyei; Pinu: P. inundatus; Plac: P. lactucaedebilis; Pmac: P. macrosporus; Ppac: P. pachydermus}

\section{Acknowledgements}

We thank Tuomas Puukko, Airi Lamminmäki, and Leena Grönholm, for excellent technical support. Computing resources provided by the Finnish IT Center for Science (CSC; www.CsC.fi) are gratefully acknowledged. We wish to thank Prof. Dr. Dominik Begerow and Prof. Daniel Croll for their critical comments on this manuscript during the external examination of Kai Wang's PhD thesis. We also would like to thank Prof. Dr. Michael Weiss and Dr. Konstanze Bensch for their guidance concerning the naming of $P$. arabidopsidicola.

\section{Adherence to national and international regulations} Not applicable.

\section{Authors' contributions}

K.O., T.S., and K.W. designed experiments, T.S. and K.W. performed experiments, K.W. performed all bioinformatics analyses. K.W. and K.O., wrote the manuscript, all authors edited and approved the manuscript.

\section{Funding}

This work was supported by the following grants: Academy of Finland Fellowship (decisions 251397, 256073 and 283254) to KO and the Academy of Finland Center of Excellence in Primary Producers 2014-2019 (decisions 271832 and 307335). KW is a member of the University of Helsinki Doctoral Programs in Plant Science (DPPS).

\section{Availability of data and materials}

The datasets generated and/or analysed during the current study are available in the repositories listed below: Gene and genome sequences used here can be accessed in GenBank, www.ncbi.nlm.nih.gov/ genbank, under the following accession numbers: For ITS sequences: Protomyces arabidopsidicola, strain C29 (Para), LT602858; P. gravidus (Pgra), MK937055; P. inouyei (Pino), MK937056; P. inundatus (Pinu), MK937057; P. lactucaedebilis (Plac), MK937058; P. macrosporus (Pmac), MK937059; P. pachydermus (Ppac), MK937060. For D1/D2 sequences: Para, MK934482; Pgra, U84342.1; Pino, NG_042406.1; Pinu, U76528.1; Plac, U84343.1; Pmac, U94939; Ppac U84345. For act1: Para, MN031257; Pgra, MN031251; Pino, MN031252; Pinu, MN031253; Plac, MN031254; Pmac, MN031255; Ppac MN031256. For rbp1: Para, MN270968; Pgra, MN270962; Pino, MN270963; Pinu, MN270964; Plac, MN270965; Pmac, MN270966; Ppac MN270967. For rbp2: Para, MN313889; Pgra, MN313883; Pino, MN313884; Pinu, MN313885; Plac, MN313886; Pmac, MN313887; Ppac MN313888. For tef1: Para, MN304745; Pgra, MN304739; Pino, MN304740; Pinu, MN304741; Plac, MN304742; Pmac, MN304743; Ppac MN304744. For tub2: Para, MN178303; Pgra, MN178297; Pino, MN178298; Pinu, MN178299; Plac, MN178300; Pmac, MN178301; Ppac, MN178302. The GenBank accession number of Protomyces arabidopsidicola strain C29 genome is QXMI00000000 and genome raw data in SRA is SRR8109439. Genome annotations available at genomevolution.org/coge/Genomelnfo.pl? with the following genome IDs: Para, 53653; Pgra, 53651; Pino, 53654; Pinu, 53676; Plac, 54947; Pmac, 53670; Ppac 54948. The Protomyces arabidopsidicola strain C29 has been deposited as the holotype in the University of Helsinki Microbial Domain Biological Resource Centre (HAMBI) Culture Collection, www.helsinki.fi/en/infrastructures/biodiversity-collections/ infrastructures/microbial-domain-biological-resource-centre-hambi, under the accession no. HAMBI3697, and an ex-holotype culture was deposited in the German Collection of Microorganisms and Cell Cultures (DSMZ) culture collection, www.dsmz.de, under the accession no. DSM 110145. The strains SC2-11 and SC2-15 are available from the same collections under the following accession numbers; strains C2-11, HAMBI 3736, DSM 111894, and C2-15,HAMBI 3737, DSM 111895. The species name Protomyces arabidopsidicola has been registered with Mycobank, http://www.mycobank.org/, under the accession no. MB 830646.

Ethics approval and consent to participate Not applicable.

\section{Consent for publication}

Not applicable.

\section{Competing interests}

The authors declare that they have no competing interests.

\section{Author details}

${ }^{1}$ Organismal and Evolutionary Biology Research Program, Faculty of Biological and Environmental Sciences, and Viikki Plant Science Centre, P.O. Box 65, Viikinkaari 1, Fl-00014 Helsinki, Finland. ${ }^{2}$ Present address: Finnish 
Institute of Molecular Medicine, University of Helsinki, P.O. Box 20, Fl-00014 Helsinki, Finland.

\section{Received: 10 December 2019 Accepted: 5 January 2021 Published online: 19 March 2021}

\section{References}

Agler MT, Ruhe J, Kroll S, Morhenn C, Kim S-T, Weigel D, Kemen EM (2016) Microbial hub taxa link host and abiotic factors to plant microbiome variation. PLoS Biology 14(1):e1002352. https://doi.org/10.1371/journal.pbio. 1002352

Bacigálová K (2008) Protomyces buerenianus (Protomycetaceae) —a new species for Slovakia. Biologia 63(1):40-43

Bacigálová K, Piątek M, Wołkowycki M (2005) Protomyces cirsii-oleracei (Fungi, Protomycetales), a new species for Poland. Polish Botanical Journal 50(1):77-82

Blackwell M (2011) The Fungi: 1, 2, 3.. 5.1 million species? American Journal of Botany 98(3):426-438

Boundy-Mills KL, Glantschnig E, Roberts IN, Yurkov A, Casaregola S, Daniel HM, Groenewald M, Turchetti B (2016) Yeast culture collections in the twenty-first century: new opportunities and challenges. Yeast 33(7):243-260

Brachi B, Filiault D, Darme P, Le Mentec M, Kerdaffrec E, Rabanal F, Anastasio A, Box M, Duncan S, Morton T, Novikova P, Perisin M, Tsuchimatsu T, Roderick Woolley R, Yu M, Dean C, Nordborg M, Holm S, Bergelson J (2017) Plant genes influence microbial hubs that shape beneficial leaf communities. bioRxiv:181198

Crous PW, Hawksworth DL, Wingfield MJ (2015) Identifying and naming plantpathogenic fungi: past, present, and future. Annual Review of Phytopathology 53:247-267

De Bary A, Garnsey HEF (1887) Comparative morphology and biology of the fungi, mycetozoa and bacteria, vol 2. Clarendon Press, Oxford

Emms DM, Kelly S (2015) OrthoFinder: solving fundamental biases in whole genome comparisons dramatically improves orthogroup inference accuracy. Genome Biology 16(1):157

Funk VA, Chan R (2009) Introduction to Cichorioideae. Systematics, evolution, and biogeography of Compositae, pp 336-342

Goris J, Konstantinidis KT, Klappenbach JA, Coenye T, Vandamme P, Tiedje JM (2007) DNA-DNA hybridization values and their relationship to wholegenome sequence similarities. International Journal of Systematic and Evolutionary Microbiology 57(1):81-91

Hibbett DS, Binder M, Bischoff JF, Blackwell M, Cannon PF, Eriksson OE, Huhndorf S, James T, Kirk PM, Lücking R (2007) A higher-level phylogenetic classification of the Fungi. Mycological Research 111(5):509-547

James TY, Kauff F, Schoch CL, Matheny PB, Hofstetter V, Cox CJ, Celio G, Gueidan C, Fraker E, Miadlikowska J (2006) Reconstructing the early evolution of Fungi using a six-gene phylogeny. Nature 443(7113):818

Konstantinidis KT, Tiedje JM (2005) Genomic insights that advance the species definition for prokaryotes. Proceedings of the National Academy of Sciences 102(7):2567-2572

Kück P, Meusemann K (2010) FASconCAT: convenient handling of data matrices. Molecular Phylogenetics and Evolution 56(3):1115-1118

Kurtzman C (1993a) The systematics of ascomycetous yeasts defined from ribosomal RNA sequence divergence: theoretical and practical considerations. In: Reynolds DR, Taylor JW (eds) The fungal Holomorph: mitotic, Meiotic Pleomorphic Speciation in Fungal Systematics. CAB International, Wallingford, pp 271-279

Kurtzman CP (1993b) DNA-DNA hybridization approaches to species identification in small genome organisms. In: methods in enzymology, vol 224. Elsevier, pp 335-348

Kurtzman CP (2011) Protomyces Unger (1833). In: Kurtzman CP, Fell JW, Boekhout T (eds) The yeasts: a taxonomic study, 5th edn. Elsevier, Amsterdam, pp 725-731

Kurtzman CP, Fell JW, Boekhout T (2011) The yeasts: a taxonomic study, 5th edn. Elsevier, Amsterdam

Kurtzman CP, Robnett CJ (1998) Identification and phylogeny of ascomycetous yeasts from analysis of nuclear large subunit (26S) ribosomal DNA partial sequences. Antonie Van Leeuwenhoek 73(4):331-371

Kurtzman CP, Sugiyama J (2015) Saccharomycotina and Taphrinomycotina: The Yeasts and Yeastlike Fungi of the Ascomycota. In: McLaughlin DJ, Spatafora JW (eds) The mycota VIl: Systematics and evolution: Part B. 2nd Edition edn Springer Berlin Heidelberg, Berlin, Heidelberg, pp 3-33. https://doi.org/10. 1007/978-3-662-46011-5_1
Larkin MA, Blackshields G, Brown N, Chenna R, McGettigan PA, McWilliam H, Valentin F, Wallace IM, Wilm A, Lopez R (2007) Clustal W and Clustal X version 2.0. Bioinformatics 23(21):2947-2948

Letunic I, Bork P (2016) Interactive tree of life (iTOL) v3: an online tool for the display and annotation of phylogenetic and other trees. Nucleic Acids Research 44(W1):W242-W245

Liu Y, Leigh JW, Brinkmann H, Cushion MT, Rodriguez-Ezpeleta N, Philippe H, Lang BF (2009) Phylogenomic analyses support the monophyly of taphrinomycotina, including Schizosaccharomyces fission yeasts. Molecular Biology and Evolution 26(1):27-34. https://doi.org/10.1093/molbev/msn221 Lohwag H (1934) Zu Lycoperdellon. Annales Mycologici 32:244-255

Mix A (1924) Biological and cultural studies of Exoascus deformans. Phytopathology 14:217-233

Nishida H, Hamamoto M, Sugiyama J (2011) Draft genome sequencing of the enigmatic yeast Saitoella complicata. The Journal of General and Applied Microbiology 57(4): 243-246

Nishida H, Sugiyama J (1994) Archiascomycetes: detection of a major new lineage within the Ascomycota. Mycoscience 35(4):361-366

Nishida H, Sugiyama J (1995) A common group I intron between a plant parasitic fungus and its host. Molecular Biology and Evolution 12(5):883-886

Piepenbring M, Bauer R (1997) Erratomyces, a new genus of Tilletiales with species on Leguminosae. Mycologia 89(6):924-936

Prior R, Mittelbach M, Begerow D (2017) Impact of three different fungicides on fungal epi-and endophytic communities of common bean (Phaseolus vulgaris) and broad bean (Vicia faba). Journal of Environmental Science and Health, Part B 52(6):376-386

Reddy MS, Kramer C (1975) A taxonomic revision of the Protomycetales. Mycotaxon 3(1):1-50

Regalado J, Lundberg DS, Deusch O, Kersten S, Karasov T, Poersch K, Shirsekar G, Weigel D (2020) Combining whole-genome shotgun sequencing and rRNA gene amplicon analyses to improve detection of microbe-microbe interaction networks in plant leaves. International Society for Microbial Ecology Journal 14:2116-2130

Riley R, Haridas S, Wolfe KH, Lopes MR, Hittinger CT, Göker M, Salamov AA, Wisecaver JH, Long TM, Calvey CH (2016) Comparative genomics of biotechnologically important yeasts. Proceedings of the National Academy of Sciences, USA 113(35):9882-9887

Rodrigues MG, Fonseca Á (2003) Molecular systematics of the dimorphic ascomycete genus Taphrina. International Journal of Systematic and Evolutionary Microbiology 53(2):607-616

Rodriguez-R LM, Konstantinidis KT (2016) The enveomics collection: a toolbox for specialized analyses of microbial genomes and metagenomes. Peer $J$ Preprints. https://doi.org/10.7287/peerj.preprints.1900v1

Ronquist F, Teslenko M, Van Der Mark P, Ayres DL, Darling A, Höhna S, Larget B, Liu L, Suchard MA, Huelsenbeck JP (2012) MrBayes 3.2: efficient Bayesian phylogenetic inference and model choice across a large model space. Systematic Biology 61(3):539-542

Rosling A, Cox F, Cruz-Martinez K, Ihrmark K, Grelet G-A, Lindahl BD, Menkis A, James TY (2011) Archaeorhizomycetes: unearthing an ancient class of ubiquitous soil fungi. Science 333(6044):876-879

Sadebeck R (1884) Untersuchungen iiber die Pilzgattung Exoascus. Jahrbuch der Hamburgischen Wissenschaftlichen Anstalten 1:93-124

Sela I, Ashkenazy H, Katoh K, Pupko T (2015) GUIDANCE2: accurate detection of unreliable alignment regions accounting for the uncertainty of multiple parameters. Nucleic Acids Research 43:W7-W14

Stamatakis A (2014) RAxML version 8: a tool for phylogenetic analysis and postanalysis of large phylogenies. Bioinformatics 30(9):1312-1313. https://doi.org/ 10.1093/bioinformatics/btu033

Stielow JB, Levesque CA, Seifert KA, Meyer W, Iriny L, Smits D, Renfurm R, Verkley G, Groenewald M, Chaduli D (2015) One fungus, which genes? Development and assessment of universal primers for potential secondary fungal DNA barcodes. Persoonia 35:242

Sugiyama J, Hosaka K, Suh S-O (2006) Early diverging Ascomycota: phylogenetic divergence and related evolutionary enigmas. Mycologia 98(6):996-1005

Sugiyama J, Nagahama T, Nishida H (1996) Fungal diversity and phylogeny with emphasis on $18 \mathrm{~S}$ ribosomal DNA sequence divergence. In: RR C, U S, K O (eds) Microbial diversity in time and space. Springer, Boston, pp 41-51

Tubaki K (1957) Biological and cultural studies of three species of Protomyces. Mycologia 49(1):44-54

Turland NJ, Wiersema JH, Barrie FR, Greuter W, Hawksworth D, Herendeen PS, Knapp S, Kusber W-H, Li D-Z, Marhold K (2018) International code of nomenclature for algae, fungi, and plants (Shenzhen code) adopted by the 
nineteenth international botanical congress Shenzhen, China, July 2017. Regnum Vegetabile 159 Glashütten: Koeltz botanical books

Unger F (1833) Die Exantheme der Pflanzen. Gerold, Wien:421

Van Eijk G, Roeymans H (1982) Distribution of carotenoids and sterols in relation to the taxonomy of Taphrina and Protomyces. Antonie Van Leeuwenhoek 48(3):257-264

Von Arx J, Weijman A (1979) Conidiation and carbohydrate composition in some Candida and Torulopsis species. Antonie Van Leeuwenhoek 45(4):547-555

Vu D, Groenewald M, Szöke S, Cardinali G, Eberhardt U, Stielow B, de Vries M, Verkleij G, Crous P, Boekhout T (2016) DNA barcoding analysis of more than 9000 yeast isolates contributes to quantitative thresholds for yeast species and genera delimitation. Studies in Mycology 85:91-105

Walker WF (1985) $5 S$ ribosomal RNA sequences from ascomycetes and evolutionary implications. Systematic and Applied Microbiology 6(1):48-53

Wang K, Sipilä T, Rajaraman S, Safronov O, Laine P, Auzane A, Mari A, Auvinen P, Paulin L, Kemen E, Salojärvi J, Overmyer K (2019) A novel phyllosphere resident Protomyces species that interacts with the Arabidopsis immune system. Biorxiv:594028. https://doi.org/10.1101/594028\%JbioRxiv

Wang K, Sipilä TP, Overmyer K (2016) The isolation and characterization of resident yeasts from the phylloplane of Arabidopsis thaliana. Scientific Reports 6:39403

Wibberg D, Rupp O, Blom J, Jelonek L, Kröber M, Verwaaijen B, Goesmann A, Albaum S, Grosch R, Pühler A (2015) Development of a Rhizoctonia solani AG1-IB specific gene model enables comparative genome analyses between phytopathogenic R. solani AG1-IA, AG1-IB, AG3 and AG8 isolates. PLoS One 10(12):e0144769

\section{Publisher's Note}

Springer Nature remains neutral with regard to jurisdictional claims in published maps and institutional affiliations.

Ready to submit your research? Choose BMC and benefit from:

- fast, convenient online submission

- thorough peer review by experienced researchers in your field

- rapid publication on acceptance

- support for research data, including large and complex data types

- gold Open Access which fosters wider collaboration and increased citations

- maximum visibility for your research: over $100 \mathrm{M}$ website views per year

At $\mathrm{BMC}$, research is always in progress.

Learn more biomedcentral.com/submissions 